Rhode Island College

Digital Commons @ RIC

Master's Theses, Dissertations, Graduate Research and Major Papers Overview

8-1-2019

\title{
Homology Modeling of the Squalus Acanthias AHR1 To Locate Structural Determinants of Function
}

Timothy Bock

Follow this and additional works at: https://digitalcommons.ric.edu/etd

Part of the Biology Commons, and the Genetics and Genomics Commons

\section{Recommended Citation}

Bock, Timothy, "Homology Modeling of the Squalus Acanthias AHR1 To Locate Structural Determinants of Function" (2019). Master's Theses, Dissertations, Graduate Research and Major Papers Overview. 307. https://digitalcommons.ric.edu/etd/307

This Thesis is brought to you for free and open access by Digital Commons @ RIC. It has been accepted for inclusion in Master's Theses, Dissertations, Graduate Research and Major Papers Overview by an authorized administrator of Digital Commons @ RIC. For more information, please contact digitalcommons@ric.edu. 
HOMOLOGY MODELING OF THE SQUALUS ACANTHIAS AHR1 TO LOCATE

STRUCTURAL DETERMINANTS OF FUNCTION

IN AN ATYPICAL RECEPTOR

by Timothy Bock Jr.

\begin{abstract}
A Thesis Submitted in Partial Fulfillment
of the Requirements for the Master of Arts in
\end{abstract}

The Department of Biology

The School of Arts and Sciences

Rhode Island College

2019 


\begin{abstract}
The aryl hydrocarbon receptor (AHR) is a ligand-activated transcription factor that mediates a toxic response to many environmental contaminants. Cartilaginous fishes, due to gene duplication events, express 4 distinct AHR genes. Squalus acanthias AHR1 (SaAHR1) does not bind to typical AHR agonists, including dioxin-like chemicals (DLCs), whereas SaAHR2 binds to DLCs and subsequently upregulates genes containing dioxin responsive elements. Three-dimensional homology models were created based upon both human HIF $1 \alpha$ and human HIF $2 \alpha$ structural templates. These models yielded different secondary structural characteristics, most notably in the length of the $\beta$-strand on the C-terminal end of the ligand binding domain, which is centrally located in the antiparallel $\beta$-sheet that makes up a large portion of the ligand binding cavity. Residue A375 is located in a possible hinge area on this $\beta$-strand, and the mutation A375C would change this alanine residue in the nonbinding SaAHR1 to its analog in the DLC-binding SaAHR2, which may increase SaAHR1's binding affinity to DLCs. The SaAHR1 also has a novel diproline motif comprising residues 379 and 380, located on the same $\beta$ strand as residue 375. This motif is not known to be found in any other AHR isoforms. Reversion of the diproline motif to proline-leucine, its analogous residues in SaAHR2, did not restore PCB 126 induced activation of a luciferase reporter gene. Epifluorescence microscopy using a heterologous expression system and an eGFP-SaAHR1 DNA construct revealed a nuclear localization unique to this isoform. Further characterization of this non-binding receptor could help to determine species-specific sensitivities to AHR agonists, especially in animals that are unavailable for direct experimentation (i.e.: endangered species).
\end{abstract}




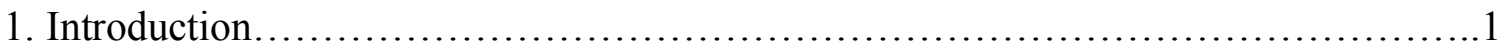

1.1 Receptor proteins....................................................

1.2 Exogenous chemicals..............................................

1.2.1 Persistent organic pollutants.................................. 3

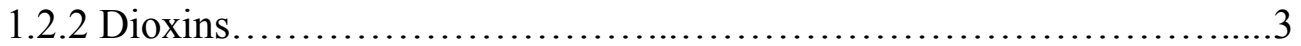

1.2.3 Polychlorinated biphenyls...................................4

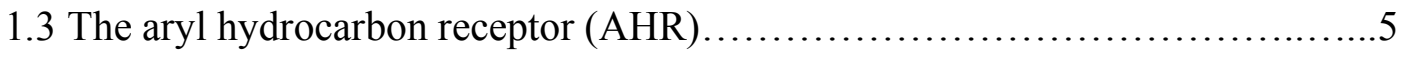

1.3.1 AHR chaperones.............................................6

1.3.2 AHR activation..............................................6

1.3.3 Physiological roles of the AHR .................................

1.3.4 Evolution of the AHR.......................................8

1.3.5 Toxicological roles of the AHR .................................8

1.4 AHR structure and modeling ........................................

1.5 Squalus acanthias as a human model................................... 10

1.6 Hypotheses...................................................... 11 
2. Methods...............................................................14

3. Results.............................................................. 20

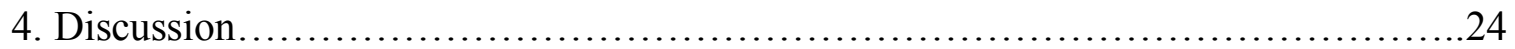

5. Acknowledgements........................................................ 30

6. Figures............................................................... 31

7. References................................................................... 51

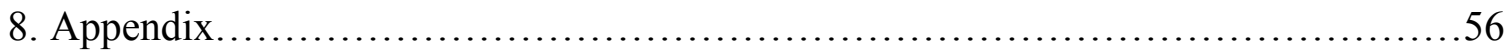




\section{Introduction}

Environmental chemical pollutants are ubiquitous. They are present in the air we breathe, the water we drink, and the food we eat. Some chemicals are transient and break down by photolysis or natural bioremediation, whereas others are incredibly stable and may not break down for decades. Unfortunately, a great deal of stable chemicals are hydrophobic and lipophilic, partitioning into the fat of an organism ${ }^{1}$. Furthermore, hydrophobic chemicals partition into plastics ${ }^{2}$, where they can pose a long-term exposure risk to the environment. These chemicals can accumulate in organisms and magnify exponentially up the food chain. This means that apex predators, including humans, will have high chemical body burdens relative to lower trophic levels ${ }^{3}$.

Another characteristic of hydrophobic or lipophilic chemicals is that they easily pass through plasma membranes ${ }^{1}$. As such, these chemicals make their way into animal cells easily, where depending on their mechanism of action, they can affect the cell on a molecular level. This molecular change can cause damage in a multitude of ways such as altering gene transcription or blocking normal functions ${ }^{4}$. This dysbiosis can affect multiple downstream processes through molecular cascade effects, which ultimately magnify the overall effect. One such interface between chemicals and cellular effects is the receptor protein.

\subsection{Receptor proteins}

Receptor proteins bind to specific chemicals and undergo changes in structural conformation, providing chemical signals for downstream processes ${ }^{4}$. A chemical that 
binds to a receptor protein is known as a ligand. A ligand can either be an agonist, which is a chemical that binds and mediates a downstream response, or an antagonist, which is a chemical that binds and causes the receptor to be nonfunctional in its normal downstream response. A receptor's affinity to bind a ligand is dependent on its biochemical properties, the functional domains it possesses, and the identity of key amino acid residues $^{5}$.

Receptor proteins can be localized in different cellular compartments, and as such will have different functions such as initiating and transmitting a signal or acting as a transcription factor ${ }^{5}$. Membrane-bound receptors recognize chemical signals outside of the cell and upon binding undergo a conformational change, normally the first step in a chemical cascade. Cytoplasmic receptors, such as the aryl hydrocarbon receptor (AHR), are localized in the cytoplasm and have various functions upon activation, including gene regulation. Nuclear receptors, such as the estrogen receptor (ER), are usually involved in gene regulation due to their proximity to $\mathrm{DNA}^{6}$. Some nuclear receptors, such as the thyroid hormone receptor are constitutively bound to their hormone receptor elements (HREs) on DNA even when inactive and bind to their respective hormones directly adjacent to the gene they regulate ${ }^{6}$.

\subsection{Exogenous chemicals}

Since the industrial revolution, humans have been polluting the environment with large volumes of chemical waste ${ }^{7}$. Chemical pollutants can originate from point sources, such as discharge pipe effluent from a manufacturing plant, or non-point sources, such as 
pesticide or fertilizer runoff from farmland ${ }^{1}$. A recent uptick in extreme weather events, attributed to global climate change, may increase the amount of chemical runoff that leads into waterways and marine environments ${ }^{8}$. Exogenous, otherwise known as xenobiotic, chemicals can interact with wildlife, induce toxicity in organisms, and cause deleterious effects on the ecological communities exposed ${ }^{1}$.

\subsubsection{Persistent organic pollutants}

Many anthropogenic chemicals, including halogenated aromatic hydrocarbons (HAHs), are persistent organic pollutants (POPs), exhibiting high stabilities and low degradation rates ${ }^{1}$. These compounds persist in the environment, bioaccumulate in individuals, and biomagnify up food-web trophic levels. Bioaccumulation occurs on the organismal level, when an individual's chemical uptake occurs faster than the chemical can be metabolized or excreted. Another key factor in bioaccumulation is the hydrophobic and lipophilic nature of many persistent chemicals, which causes partitioning into an individual's fatty tissues, where any metabolism may be reduced. Biomagnification occurs at higher trophic levels when an individual consumes numerous animals of lower trophic levels, each of which have accumulated a chemical burden throughout their lifetime. Apex predators are at the highest risk of increased lipophilic chemical load due to both biomagnification and bioaccumulation ${ }^{1}$.

\subsubsection{Dioxins}

Dioxins are chemical byproducts of volcanos and other combustion events and have been present in the environment for billions of years ${ }^{1}$. Although dioxins are 
produced from these natural sources, much more has been released into the environment from industrial processes ${ }^{9}$. A few examples of industrial dioxin sources include effluent waste from the manufacturing of some pesticides and herbicides, and processes such as smelting and bleaching of paper pulp 9 . A well-known dispersal of dioxins occurred during the Vietnam war as an unintended ingredient in the military defoliant known as Agent Orange ${ }^{10}$.

2,3,7,8-tetrachlorodibenzo- $p$-dioxin (TCDD), one of the most potent and wellstudied dioxins, is of special interest to AHR chemistry because this co-planar molecule binds to most mammalian AHRs with the highest affinity of any known AHR agonist ${ }^{11}$. Because of this high affinity to AHRs, TCDD is often used as a model coplanar chemical to study the binding properties of AHR:agonist relationships.

\subsubsection{Polychlorinated biphenyls}

Polychlorinated biphenyls (PCBs) are a group of environmental pollutants that were used heavily in industry for their high stability ${ }^{1}$, which is ironically the same characteristic that makes these chemicals persist in the environment. These legacy chemicals, although banned by most countries, are still present in the environment in high concentrations, especially in sites where they were produced or dumped. One such contaminated site is New Bedford Harbor, Massachusetts, in which two electrical component plants used and improperly disposed of PCB-mixtures called Aroclors for 30 years before production was outlawed in the United States in $1978^{12}$. Remediation of this area is still ongoing, with approximately 485,000 cubic yards of sediment dredged and 
disposed of as of September $2018^{13}$. Some congeners of PCBs are co-planar chemicals and are considered dioxin-like compounds (DLCs) due to their structural similarities to $\mathrm{TCDD}^{14}$. These co-planar PCBs are of interest to researchers due to a high affinity to mammalian AHRs ${ }^{11}$.

\subsection{The aryl hydrocarbon receptor}

The aryl hydrocarbon receptor (AHR) is a cytosolic ligand-activated transcription factor in the basic-helix-loop-helix Per-ARNT-Sim (bHLH-PAS) family of environmental sensor proteins ${ }^{15}$. AHR binds with high affinity to a number of structurally related xenobiotic toxins, such as halogenated aromatic hydrocarbons $(\mathrm{HAH})$ and polycyclic aromatic hydrocarbons $(\mathrm{PAH})$, and mediates their toxic effects ${ }^{16}$. Potentially harmful AHR agonists have been found in many products consumers use daily, such as newspaper ink and rubber ${ }^{17}$. The AHR also binds to many nontoxic ligands, including endogenous chemicals such as tryptophan derivatives, and mediates normal physiological responses such as regulating immune function ${ }^{18}$.

The superfamily of basic-helix-loop-helix Per-ARNT-Sim (bHLH-PAS) environmental sensor transcription factors control expression of homeostatic genes. This protein family also includes but is not limited to hypoxia inducible factor (HIF), single minded protein (SIM), and circadian locomotor output cycles kaput (CLOCK) ${ }^{19}$. In each of these proteins, the bHLH domain interacts directly with enhancer sequences on target genes to control gene activation, whereas PAS domains usually control activation or ligand binding and a subsequent dimerization step necessary to create a transcription 
factor complex ${ }^{19}$. These domains work in conjunction to provide bHLH-PAS transcription factors with signal-induced control over a subset of the cell's transcriptional output. bHLH-PAS proteins exhibit sequence homology and as such are considered evolutionarily related ${ }^{19}$.

\subsubsection{AHR chaperones}

Prior to ligand binding, the AHR is complexed with the chaperone proteins AHRassociated protein 9 (ARA9), heat shock protein 90 (HSP90), and the cochaperone prostaglandin E synthase 3 (PTGES3, also known as P23). A homodimer of HSP90, which is named due to its molecular weight of 90 kilodaltons $(\mathrm{kDa})$, helps maintain an "open" conformation in the AHR ligand-binding cavity and blocks the DNA-binding domain (DBD), preventing premature DNA binding ${ }^{20}$. ARA9, also known as AHRinteracting protein (AIP) and xenobiotic-associated protein 2 (XAP2), has a molecular weight of $37 \mathrm{kDa}$ and is thought to protect the AHR complex from proteasomal degradation and control AHR's cellular localization ${ }^{21}$. The cochaperone P23 is necessary for the ligand-dependent translocation of AHR, the dissociation of the HSP90 dimer, and protects the AHR from degradation ${ }^{22}$.

\subsubsection{AHR activation}

Once ligand binding occurs, the AHR translocates into the nucleus, where it dimerizes with its partner protein, the aryl hydrocarbon receptor nuclear translocator (ARNT) (Figure 1). The newly formed AHR:ARNT heterodimer acts as transcription factor, upregulating genes that contain a dioxin responsive element (DRE), also known as 
a xenobiotic responsive element (XRE), in their promoter regions ${ }^{23}$. The collection of genes under the transcriptional control of AHR, known as the AHR gene battery, includes hundreds of genes and controls many physiological functions, including xenobiotic metabolism, immune system function, growth, and development ${ }^{24}$.

\subsubsection{Physiological roles of the AHR}

The AHR, besides being a xenobiotic sensor protein, has multiple roles in normal physiological development. The AHR modulates expression of the estrogen receptor 1 (ESR1), estrogen related receptor alpha (ESRRA) and estrogen related receptor gamma $(\mathrm{ESRRG})^{24}$. Cytochrome P450 17A1 (CYP17A1) mRNA levels are affected by the AHR, catalyzing steps in the biosynthesis of steroid precursors ${ }^{24}$. Neuronal pentraxin I (Nptx1), also upregulated by AHR activation, is part of the neuronal stress pathway involved in $\operatorname{apoptosis}^{24}$

Untreated AHR knockout mice were shown to have compromised hepatic function and patent ductus venosus of the liver ${ }^{25}$, suggesting the need for a functional AHR in normal liver development. Activation of the AHR has been shown to affect human hematopoietic progenitor cell differentiation, with agonism leading to expansion of erythroid differentiation and antagonism leading to differentiation into megakaryocytes ${ }^{26}$.

Many studies suggest that the AHR plays a vital role in the regulation of the immune system. Commensal gut microbes are known to metabolize dietary tryptophan, creating kynurenines that activate the host's AHR signaling pathway, ultimately 
regulating immune response and gut homeostasis ${ }^{18}$. It has been suggested that the human AHR has adapted to ligands produced by native gut microbiota, providing an immune response that regulates host-microbe homeostasis, and exhibits a 2:1 binding stoichiometry to indole, which has not been seen with other AHR ligand-receptor pairings ${ }^{27}$. The AHR may also play a future role in the treatment in autoimmune diseases, as AHR activation by TCDD has ameliorated experimentally induced colitis in mice by upregulating regulatory $\mathrm{T}$ cells and down regulating $\mathrm{T}$-helper $17 \mathrm{cells}^{28}$. Interestingly, activation of AHR with an endogenous ligand, 6-Formylindolo[3,2-b]carbazole (FICZ), caused the upregulation of T-helper 17 cells, increasing imflammation ${ }^{28}$.

\subsubsection{Evolution of the AHR}

The AHR is present in all Metazoan groups and has evolved independently in these diverse lineages. Mammalian AHRs are the most well studied and differences in species have been utilized to help characterize determinants of binding affinities to AHR agonists ${ }^{29}$. Non-mammalian vertebrate species exhibit a greater diversity of AHRs, with many species of fish containing more than one AHR gene - often expressed in different tissues and with varying affinities to DLCs ${ }^{30}$.

Sharks and other cartilaginous fishes have four distinct AHR genes and can synthesize multiple aryl hydrocarbon receptor (AHR) isoforms ${ }^{30}$. Spiny dogfish shark (Squalus acanthias) AHR1 does not bind to typical dioxin-like ligands, however AHR2 and AHR3 bind to dioxin-like chemicals and subsequently upregulate genes containing the dioxin responsive element (DRE) promoter region ${ }^{31}$. There is currently no binding 
information available for the fourth spiny dogfish AHR isoform, AHR1X, which has high sequence homology to the mammalian AHR, suggesting it may be the ancestral ortholog to the human $\mathrm{AHR}^{31}$.

\subsubsection{Toxicological roles of the AHR}

AHR ligands, especially synthetic and anthropogenic ligands, have been implicated in many situations where environmental and human health is at risk. One wellknown risk for human health is the AHR-dependent metabolism of benzo[a]pyrene $(\mathrm{BaP})$, a carcinogenic byproduct of combustion that is found in smoke and charred foods. BaP is metabolized by cytochrome P450 1A1 (CYP1A1), part of the AHR gene battery. Metabolism of BaP forms an oxidized product, which can bind to and break DNA, damaging genetic information ${ }^{32}$. Other highly toxic AHR ligands, such as TCDD and PCBs, can cause developmental deformities, general dysbiosis, cancer, and even death in high enough doses ${ }^{33}$, but the mechanisms of DLC-mediated toxicity have not been fully elucidated. The AHRs of many species of vertebrates exhibit a highly variable sensitivity to DLCs, with some AHRs exhibiting no affinity for DLCs ${ }^{34}$.

For species with functional AHRs, differences in sensitivities are predictive of toxicity. Many studies have been completed in order to characterize the determinants of

sensitivity $^{35,36,37}$, which can include ligand-binding affinity as well as the gene targets of the activated AHR:ARNT transcription factor complex. In these studies, site-directed mutagenesis is often used in conjunction with homology modeling to locate amino acids of interest and mutate them to test their biochemical effects. 


\subsection{AHR Structure and modeling}

Protein function is determined by three-dimensional structure, which can be derived via direct experimental methods, such as x-ray crystallography, nuclear magnetic resonance (NMR), or cryo-electron microscopy. In some cases, protein structures cannot be experimentally derived, due to a variety of possible hinderances. In these cases, scientists can use computational methods to predict a protein's structure in silico and create a three-dimensional model. These models allow researchers to accurately estimate the structure of a protein domain to guide experimental questions.

Homologous protein sequences can be computationally modelled based on a known template structure. Usually, protein structures used as scaffolding to model other proteins share a relatively high percentage of amino acid identity because the proteins are evolutionarily related.

Previous studies have shown that AHR homology models can be used to target amino-acid substitutions that may enhance binding in AHRs with low affinity to dioxinlike compounds. The Danio rerio AHR1a does not bind TCDD, but binding was restored with Y296H and T386A (which correspond to mouse 285 and 375) mutations, although these mutants were not able to restore AHR gene battery activation ${ }^{38}$. A similar study investigated the Xenopus laevis AHR1 $\beta$, which binds TCDD with low affinity. In the Xenopus study, the mutations N325S, A354S, and A370S (which correspond to mouse 321,359 , and 375) all increased the AHR1 $\beta$ 's affinity to TCDD ${ }^{39}$. Both of these studies used the HIF2 $\alpha$ structural template as the basis for their homology models and 
demonstrate that homology modeling, in conjunction with site-directed mutagenesis, can be used to characterize binding determinants residing in the AHR's ligand-binding domain.

\subsection{Squalus acanthias as a human model}

Elasmobranchs have long been used as vertebrate models because they are among the most primitive species exhibiting characteristics associated with human anatomy and physiology. These characteristics include the use of signaling molecules distributed via a closed circulatory system, molecular responses for salt/water homeostasis, and xenobiotic transport systems ${ }^{40}$. S. acanthias, also known as the spiny dogfish shark, is often used as a model elasmobranch due to its abundance and small size. It usually resides at depths of up to 3000 feet in cold water and may live up to 100 years. The cold temperatures of its habitat reduce the metabolic rate of this shark species and it also demonstrates resistance to normal hypoxic responses ${ }^{40}$.

\subsection{Hypotheses}

The aim of this study is to characterize key amino acid residues in the Squalus acanthias AHR1 (SaAHR1) ligand-binding domain LBD that may restore binding of SaAHR1 to dioxin-like chemicals. By characterizing binding determinants of the $S$. acanthias AHRs, we can better understand the differential binding affinities of AHR paralogs and orthologs and how this translates to sensitivity to toxic AHR agonists. In this study, I will test hypotheses about the functional significance of specific amino acid 
residues in the LBD of SaAHR1 using homology modeling and experiments with heterologous expression system-reporter gene assays.

Part of this study was a collaborative effort with the Bonati Laboratory. This involved making DNA constructs that code for point mutations to the SaAHR1 amino acid sequence recommended by the Bonati Laboratory's structural homology modeling (based on the HIF2 $\alpha$ structure). These SaAHR1 mutant constructs include 3 single mutants (R310C, L342M, and A359S) and 2 double mutants (R310C \A359S and $\mathrm{L} 342 \mathrm{M} \backslash \mathrm{A} 359 \mathrm{~S})^{\mathrm{A}}$.

During my analysis of the amino acid sequences, I discovered that the SaAHR1 has a proline in position 380. The proline in this position is unique to SaAHR1 and does not appear in any other known isoform. Furthermore, this proline forms a diproline motif toward the C-terminal end of the LBD, which could greatly affect the secondary structure of this area considering proline's rigidity regarding side chain rotation. An analysis of diproline segments in proteins has suggested that most diproline segments exist in only a few conformations and are affected by the amino acids flanking each side ${ }^{41}$. My hypothesis is that the diproline segment in SaAHR1 doesn't allow for the rotational flexibility normally seen in AHR LBDs and therefore may restrict the overall structure and function of the protein. I will be creating duplicates of the aforementioned mutant constructs (from the Bonati laboratory's recommendations), but also each with the P380L mutation (P380L, R310C \P380L, L342M \P380L, A359S \P380L, R310C \A359S \P380L,

\footnotetext{
A Corrada D and Bonati L. Department of Earth and Environmental Sciences, University of Milano-Bicocca. Milan, Italy.
} 
and $\mathrm{L} 342 \mathrm{M} \backslash \mathrm{A} 359 \mathrm{~S} \backslash \mathrm{P} 380 \mathrm{~L}$ ), in order to test whether or not this novel diproline motif affects SaAHR1's functional characteristics.

After my analysis of the SaAHR1 primary structure, I determined that more information could be gathered by analyzing the tertiary structure and created my own 3D structural models of the SaAHR1. The models I've created are based on the human HIF $1 \alpha$ structure, which is different than most AHR homology modeling studies that have been done in the past, including the Bonati collaboration. These models have helped to locate amino acid residues of interest for future studies. I have created a mutant SaAHR1 construct to change one of these residues of interest (A375C). This specific residue has been implicated as a binding determinant in multiple studies of other AHR isoforms $\mathrm{s}^{38,39,42}$. This alanine residue is part of a "faced-pair" of amino acid residues (359, 375) that point inward toward the AHR ligand-binding cavity.

If any of these specific amino acid residue changes in the LBD restore SaAHR1's binding affinity to DLCs and subsequent activation, the presence or absence of such residues may be used to predict species at risk to the toxic effects mediated by activation of the AHR pathway. 
2. Methods

\subsection{Homology Modeling}

AHRs of multiple species were chosen for alignment based upon varying affinities for dioxin-like chemicals (Table 1). Alignments of the amino acid residues in the AHR ligand binding domains (LBDs) of multiple species were created using the ClustalW ${ }^{43}$ alignment tool in MacVector version 15.5.4 (Figure 2).

Three-dimensional structural models (.pdb format) of the AHR LBDs were created for a subset of the aligned isoforms (SaAHR1, 2, 3 and MmAHR) using MODELLER version 9.21 44,45 via the University of California San Francisco (UCSF) Chimera version 1.11.2 $2^{46}$. The basic local alignment search tool (BLAST) ${ }^{47}$ was used to query the Protein Data Bank $(\mathrm{PDB})^{48}$ to find known protein structures that share the highest percentage amino acid identity. The search result with the highest percent homology was used as a structural template to model the AHR LBDs, in this case human hypoxia inducible factor $1 \alpha(\mathrm{HIF} 1 \alpha)$ (PDB ID: 4H6J_A ${ }^{49}$ ) and human HIF2 $\alpha$ (PDB ID: $1 \mathrm{P} 97^{50}$ ) (Table 2). 10 output models were built for each AHR isoform with "build models with hydrogens" and "thorough optimization" options enabled. One representative model for each of the modeled ligand binding domains was chosen based upon their MODELLER-derived GA341 ${ }^{51}$, where a value greater than 0.70 is correlated to a $95 \%$ probability that a model has the correct fold ${ }^{52}$, and $\mathrm{zDOPE}^{53}$ (normalized discrete optimized protein energy), where negative values are preferable scores ${ }^{52}$ (Appendix 1). A 
qualitative analysis comparing both the amino acid alignments and the structural models was undertaken to identify residues of interest for site-directed mutagenesis.

\subsection{Mutagenic Primer Design}

Specific amino acid changes (R310C, L342M, A359S, R310C $\backslash$ L342M, and L342M $\backslash A 359 S$ ) were recommended by a computational analysis performed by the Bonati Laboratory. Other residues of interest (A375C and P380L) were identified via the computational analysis I performed. Mutagenic primers were designed using the QuikChange Primer Design online tool available from Agilent (Table 3). Polyacrylamide gel electrophoresis (PAGE) purified primers were ordered from Integrated DNA Technologies (IDT).

\subsection{Chemicals}

3,3',4,4',5-Pentachlorobiphenyl (PCB 126) in dimethyl sulfoxide (DMSO), 2 mg/ml, was obtained from AccuStandard, Inc (CAS\# 57465-28-8, 99.5\% purity).

\subsection{Cell Culture}

Mammalian cell-cultures were maintained at $37^{\circ} \mathrm{C}$ with $5 \%$ supplemental $\mathrm{CO}_{2}$. COS7 cells (green monkey kidney epithelial cells, ATCC CRL-1651) were maintained in Dulbecco’s Modified Eagle’s Medium (DMEM, Sigma D7777), supplemented with 3.7 g/L NaHCO3, with 10\% fetal bovine serum (FBS) added. C35 cells (mouse liver hepatoma cells, derived from Hepa-1c1c7, ATCC CRL-2715) were maintained in alpha 
minimum essential medium ( $\alpha$ MEM, ATCC 30-2605), supplemented with L-glutamine ( $2 \mathrm{mM}$ final concentration), with $10 \%$ heat-inactivated FBS added.

\subsection{Expression Constructs}

Full length Squalus acanthias AHR1 and AHR2 were cloned into DEST53 expression vectors using the Gateway system prior to this project by the Merson Laboratory (Table 4). This DNA construct is expressed under the control of a cytomegalovirus (CMV) promoter and encodes an N-terminal eGFP-AHR fusion protein. An inducible firefly luciferase, pGudLuc 6.1, was a gift from M. Denison from University of California, Davis. A constitutive Renilla luciferase, pRL-TK, was included in the Promega Dual Luciferase Reporter Assay Kit. Full length Fundulus heteroclitus FhAHR2 and FhARNT2 were a gift from M. Hahn from Woods Hole Oceanographic Institution. A constitutive firefly luciferase, pGudLuc 4.13, was a gift from Promega technical support and was used to verify adequate transfection.

\subsection{SaAHR1 Site-Directed Mutagenesis}

Site-directed mutagenesis was performed on the pDEST53SaAHR1 DNA construct previously created by the Merson Laboratory. Site-directed Mutagenesis was performed using a QuikChange Lightning Multi Site-Directed Mutagenesis Kit using an Eppendorf thermal cycler. The pDEST53SaAHR1 wildtype construct (50 ng), the mutagenic primer $(100 \mathrm{ng})$, a dNTP mix $(1 \mu \mathrm{l})$, the QuikChange Lightning Multi enzyme blend $(1 \mu \mathrm{l})$, and the 10x QuikChange Lightning Multi reaction buffer $(2.5 \mu \mathrm{l})$ was placed into a reaction tube in MilliQ water to a final volume of $25 \mu$. This mixture was cycled 
(Table 5) and a proprietary DpnI restriction enzyme (10 units) was added afterward to digest the parental DNA strands. Digested DNA was transformed into ultracompetent XL-10 gold Escherichia coli, which were included in the kit, plated onto Luria broth (LB)-ampicillin (100 $\mu \mathrm{g} / \mathrm{ml})$ agar plates, and incubated overnight at $37^{\circ} \mathrm{C}$. Two colonies were chosen from each plate and grown in $5 \mathrm{ml}$ LB-ampicillin $(50 \mu \mathrm{g} / \mathrm{ml})$ cultures overnight at $37^{\circ} \mathrm{C}$ with shaking at $250 \mathrm{rpm}$. Plasmid DNA was isolated from $5 \mathrm{ml}$ cultures via QIAGEN Plasmid Mini Spin Kit (12125) using manufacturer's protocols. Multiple mutant eGFP-SaAHR1 DNA constructs were created (Table 4) for future analysis. Each mutant construct was analyzed via DNA gel electrophoresis $(0.8 \%$ agarose, 150V, 1 hour), and nanodrop spectroscopy. Specific mutations were confirmed via Sanger sequencing and subsequent analysis with MacVector version 15.5.4.

\subsection{Immunoblotting}

To confirm that the expression constructs were active in the cell line, pDEST53SaAHR1 wildtype and mutant constructs (6 $\mu \mathrm{g}$ DNA/transfection) were transfected into COS7 cells in confluent T25 flasks using X-tremeGENE HP (6 $\mu 1 /$ transfection) transfection reagent. After 72 hours, cells were lysed using $700 \mu \mathrm{l}$ Cellytic M (Sigma C2978) with cell-scraping necessary, and $10 \mu$ protease inhibitor cocktail (Sigma P8340) was added. Lysates (10 $\mu 1 /$ sample) were prepared with $2 \mathrm{X}$ protein loading dye ( $9.5 \mu 1 /$ sample), $\beta$-mercaptoethanol $(0.5 \mu 1 /$ sample), and boiled for 5 minutes. Lysate preparations ( $20 \mu \mathrm{l} /$ well) were resolved via SDS-PAGE using BIO-RAD mini-PROTEAN Tetra apparatus with precast BIO-RAD Mini-PROTEAN TGX stainfree gradient gels (4-15\%). The resolved proteins were transferred onto a GE Amersham 
Protran nitrocellulose membrane $(0.45 \mu \mathrm{m}$ pore size $)$ using a BIO-RAD Trans-Blot semidry transfer apparatus (15V, 0.9 hours). Western blotting, using rabbit anti-GFP-Nterminal primary antibody (Sigma G1544, 1:500 concentration) and goat anti-rabbit horseradish peroxidase conjugated secondary antibody (Sigma A275, 1:10,000 concentration), was performed to confirm eGFP-SaAHR1 fusion protein identity. The Western blot was visualized using BIORAD Clarity (170-5061) enhanced chemiluminescence reagents and a BIORAD ChemiDoc MP.

\subsection{Dual luciferase reporter gene assays}

C35 cells were seeded in 48-well plates at 30,000 cells/well 24 hours prior to transfection (Figure 3). At the time of transfection, medium was refreshed using $\alpha \mathrm{MEM}$ containing $10 \%$ heat-inactivated-FBS. pDEST53SaAHR1 wildtype or mutant constructs were co-transfected along with pGudLuc 6.1, pRL-TK, and FhARNT2 (Table 6, assay 6) using the lipofectamine $2000(1 \mu \mathrm{l} /$ well $)$ transfection reagent in serum-free $\alpha \mathrm{MEM}$. We used the pDEST53SaAHR2 construct as an inducible positive control and pcDNA empty vector as a negative control. 24 hours post-transfection, $1.5 \mu 1$ of either a DMSO only control or PCB 126 in DMSO (100 nM final concentration) was added to each well, using three replicate wells for each treatment group. A passive lysis buffer $(100 \mu l)$ was added to each well and the lysates used for luciferase reporter gene AHR activation assays. A Turner Biosystems 20/20 luminometer and Promega Dual-Luciferase Reporter Assay System Kit was used to quantify luminescence in order to assess AHR activation (Figure 4). The pGudLuc 4.13 plasmid was also used as a constitutively expressed positive control to confirm adequate transfection. 


\subsection{Epifluorescence Microscopy and AHR Localization Assays}

Two 12-well glass bottom plates were seeded with COS7 cells $\left(7.5 \times 10^{6}\right.$ cells/well, 24 hours prior to transfection). Medium was refreshed just prior to transfection with DMEM containing 10\% FBS. Each well was transfected with pDEST53SaAHR1 wildtype, mutants, or pDEST53SaAHR2 (1 $\mu \mathrm{g}$ DNA/well) using X-tremeGENE HP transfection reagent ( $3 \mu \mathrm{l} /$ well) in serum-free DMEM. One 12-well glass bottom plate was used as a vehicle-only ( $2.5 \mu \mathrm{l} \mathrm{DMSO} /$ well) control, and one 12-well glass bottom plate was dosed with PCB $126(2.5 \mu \mathrm{l}$ of $20 \mu \mathrm{M}$ PCB 126 in DMSO, for a final concentration of $50 \mathrm{nM}$ ). An Olympus IX81 microscope was used to visualize the eGFPSaAHR fusion proteins via epifluorescence on the FITC channel (excitation: 469-509 nm, emission: 488-528 nm). Images were taken with a Retiga camera using Q Imaging software 32 hours after dosing using the microscope's 20X objective. 
3. Results

\subsection{Homology models suggest residues of interest for SaAHR1 ligand binding}

To determine amino acid residues that differ among various isoforms of AHR with differential binding affinities, a ClustalW alignment of ligand binding domains (residues 278-385) was generated. This alignment revealed distinct amino acid residues of interest for further analysis (Figure 2). The residue P380 is of great interest in the SaAHR1, because it is not known to be present in any other AHR isoforms. This residue creates a novel diproline motif toward the C-terminal side of the LBD, which could restrict the overall structure, and therefore affect the function, of the SaAHR1.

BLAST results of LBDs selected for 3D structural modelling (SaAHR1, SaAHR2, SaAHR3, and MmAHR) show that the proteins with known structure and the highest percent homology are human hypoxia inducible factor $1 \alpha$ (HIF1 $\alpha$, PDB ID: 4H6J_A ${ }^{49}$ ) and human hypoxia inducible factor $2 \alpha$ (HIF2 $\alpha$. PDB ID: 1 P97 ${ }^{50}$ ) (Table 2). The two sets of structural models created from these scaffolds allowed for further scrutinization of residues of interest, such as their 3D location, and the possible relation of each residue's sidechain to the ligand binding cavity (Figures 5-8, 14). In the analysis that follows, I have adopted the secondary structure nomenclature used in other AHR LBD studies ${ }^{39,54}$ (Figure 5).

My analysis of these two modeling scaffolds reveals overall agreement in much of the modelled ligand binding domain. There are some basic secondary structure differences in the models. The HIF $1 \alpha$-based models (Figure 6) split both the G $\beta$ and H $\beta$ 
strands into two separate strands each, which I will refer to as $G \beta_{1}, G \beta_{2}, H \beta_{1}$, and $H \beta_{2}$ (Figure 5). The HIF2 $\alpha$-based models maintain a closer structural resemblance to the HIF $2 \alpha$ template (Figure 6). Another notable difference between HIF1 $\alpha$ and HIF2 $\alpha$ based models is the length of the $\beta$-strand on the C-terminal end of the LBD, I $\beta$. All of the models generated based upon HIF $1 \alpha$ terminate the I $\beta$-strand around residue 375 , bending the I $\beta$-strand away from the interior of the ligand binding cavity, disagreeing with the original HIF $1 \alpha$ template The models based on HIF2 $\alpha$ more closely resemble the I $\beta$-strand in the HIF $2 \alpha$ template. The exception to the larger I $\beta$-strand in the HIF2 $\alpha$-based models is the SaAHR1 WT. This model bends the I $\beta$-strand away from the ligand binding cavity around residue 375, similar to the HIF1 $\alpha$ models (Appendix 2).

The mutations recommended by the Bonati Laboratory were visualized in the HIF1 $\alpha$-based models, comparing the residue side chains between SaAHR1 and SaAHR2 (Figure 8 A-C). For each of the three mutations (R310C, L342M, and A359S) the SaAHR1 residue was mutated to its analogous residue in the SaAHR2. The mutation $\mathrm{R} 310 \mathrm{C}$ (Figure 8A) is pointed away from the ligand-binding cavity in the flexible belt portion of the AHR LBD. The mutations L342M and A359S (Figures 8B, 8C) are located on the internal side of the $\beta$-sheet that creates the ligand-binding cavity.

According to my analysis of the 3D models, the SaAHR1 residue A375 (Figure 8D) is of interest due to its side chain chemistry, location, and importance in previous studies of other AHR isoforms. It is centrally located, pointing inward toward the ligand binding cavity. This residue is a cysteine in the SaAHR2 isoform, which readily binds to DLCs, and the cysteine's sidechain chemistry may restore binding affinity to the 
SaAHR1 A375C mutant construct (which was created during this study but not yet tested).

3.2 SaAHR1 mutant constructs contain verified mutations and express protein in COS7 cells.

In order to verify the presence and size for each DNA mutagenesis construct plasmid preparation, each construct was resolved via gel electrophoresis (Figure 9). This DNA gel shows the presence of each mutant plasmid isolated from an individual plated colony, and the size of each mutant plasmid is consistent with the wildtype pDEST53SaAHR1 (8935 bp). To verify successful introduction of specific mutations, each mutant construct (except A375C) was analyzed via Sanger sequencing and did contain their respective mutations (Figure 10). Western blotting of a subset of mutants suggests that the mutant protein is expressed and is consistent in size with the wildtype pDEST53SaAHR1 eGFP fusion protein (calculated at 131.5 kDa) (Figure 11).

\subsection{Reversion of the SaAHR1 diproline motif with the P380L mutation does not restore inducible activation with PCB 126.}

To determine whether the diproline motif impaired DLC binding and SaAHR1 activation, a dual luciferase reporter gene assay was conducted. There was no difference in activation of the reporter in SaAHR1 WT (with diproline present) and SaAHR1 P380L (with diproline reverted) (Figure 12), suggesting that the diproline alone was not implicated in the nonbinding character and lack of transactivation activity. This experiment was performed with FhARNT2 co-transfected to determine if ARNT was a 
limiting factor in previous experiments (Appendix 3), with similar results reported both with and without ARNT.

Luciferase assays were also used to assess activation of the pDEST53SaAHR1 double mutants R310C/A359S and L342M/A359S (Appendix 4). These results were not included here due to low raw luminescence readings, possibly due to low transfection efficiency of the luciferase-encoding plasmids (Appendix 5).

\subsection{Epifluorescence microscopy shows a unique localization of SaAHR1 WT and mutants.}

To determine the localization of the SaAHR1 protein in the heterologous expression system, transfected cells were visualized via N-terminal eGFP-SaAHR fusion protein and imaged (Figure 13). The images show some portion of the GFP-tagged protein, representing SaAHR1 WT, SaAHR1 mutants, and SaAHR2, is translocated to the nucleus in the COS7 cells, even in vehicle-only control wells. This is unexpected due to the mechanism of AHR activation, normally translocating to the nucleus only after agonist-binding. The P380L mutant seemed to exhibit the lowest amount of nuclear localization of any of the tested constructs. 


\section{Discussion}

The models produced with the MODELLER function of the UCSF Chimera program produced interesting results. One notable difference between using human HIF $1 \alpha$ as a template and using human HIF2 $\alpha$ as a template is the size of the modelled ligand binding cavity. In the HIF $1 \alpha$ based models, the overall size of the ligand binding cavity seems greatly reduced compared to the HIF $2 \alpha$ models. This is in part due to the length of the $\beta$-strand on the C-terminal end of the LBD, I $\beta$. The HIF $1 \alpha$-based models all terminate the I $\beta$-strand around residue 375, presumably due to the lack of homologous residues past that point (Appendix 8). These models all bend the I $\beta$-strand away from the interior of the ligand binding cavity, creating a much smaller antiparallel $\beta$-sheet and thus a smaller surface area for binding to occur.

The HIF $2 \alpha$ template allows for the SaAHR2 and SaAHR3 models to more closely conform to the I $\beta$-strand in the HIF $2 \alpha$ structure due to a homologous leucine 380 residue. Interestingly, this is the same position that creates the diproline motif in the SaAHR1 isoform. Presumably, this lack of the homologous leucine 380 residue causes the SaAHR1 HIF2 $\alpha$-based model to more closely resemble the HIF1 $\alpha$-based models, bending the I $\beta$-strand away from the ligand binding cavity (Appendix 2). Usually, $\beta$-strands in antiparallel $\beta$-sheets will have a primary amino acid structure that alternates amino acid side chain character between hydrophobic and hydrophilic ${ }^{5}$. The homology modelling programs could more closely rely on homology alone, forcing models to conform to the known structure rather than using the actual side chain biochemical properties to determine secondary and tertiary structure formation. If the real structure of some AHRs 
more closely resemble that of HIF $1 \alpha$, the HIF $2 \alpha$ homology models could be greatly overestimating the size of the $\beta$-sheet that makes up a large portion of the ligand binding cavity.

Both HIF1 $\alpha$-based and HIF2 $\alpha$-based structural models have a similar "flexible belt area", which was previously theorized to be critical for ligand binding ${ }^{54}$. The amino acid residues that Xing, et al. hypothesized to be critical to ligand binding in MmAHR (F318 and I319) are conserved in all SaAHR isoforms. The same study also found that G315 is critical for MmAHR belt flexibility, and this residue is also conserved in all SaAHR isoforms. If the flexible belt area is well conserved in most AHR isoforms, and is critical for ligand binding, then the area opposite the flexible belt (the $\beta$-sheet) could cause the differences in binding affinities that we see in some AHR isoforms. This concept has been tested in many studies, and multiple residues in the interior-facing portion of the $\beta$-sheet have been mutated and resulted in a higher binding affinity to $\operatorname{DLCs}^{38,39,42}$.

Some of the studies that have increased binding affinity with certain mutations to residues in the $\beta$-sheet share these homologous residues in the SaAHR1 LBD. In birds, the AHR1 has been suggested to have a faced residue pairing of great importance (359 and 375$)^{42}$. When one of these residues is alanine and the opposite is serine, the AHR will have a higher binding affinity than if both were alanine. In Xenopus laevis, AHR1 $\beta$ was mutated to increase its affinity for TCDD using mutations analogous to A359S and $\mathrm{A} 375 \mathrm{~S}^{39}$. 
The residues on the interior portion of the ligand binding cavity could be interacting to form a charged surface. The HIF $1 \alpha$ models of the SaAHRs bend the I $\beta$ strand away from the interior of the ligand-binding cavity around residue 375 . In SaAHR2, which binds to DLCs, the cysteine 375 residue in that location pulls away from the interior cavity further than the alanine 375 in the SaAHR1 model. If these models are accurate, the I $\beta$-strand could be key to understanding the variable ligand binding properties of the SaAHRs. If this I $\beta$-strand is part of a hinge that imparts some amount of flexibility into the SaAHRs, it could "close" upon ligand binding, thus enlarging the antiparallel $\beta$-sheet and providing a more sterically favored area for dimerization with ARNT.

Residue 375 is also adjacent to other residues of interest, 342 and 359, and together these residues could create a localized area that is more favorable for binding DLCs. This may be a good example of how multiple residues interact to form a charged surface in a ligand binding cavity (Figure 14). I've created a pDEST53SaAHR1 construct with the mutation A375C for future study to test the effect of this residue's chemistry on the binding ability of the SaAHR1's LBD.

The luciferase reporter gene assays testing the SaAHR1 P380L mutant suggests no difference in activation when compared to SaAHR1 WT (Figure 12). This experiment was previously performed without cotransfection of a Fundulus heteroclitus ARNT2 construct. The addition of FhARNT2 in assay 6 (Figure 12) was to determine if ARNT was a limiting factor in the $\mathrm{C} 35$ cell line used for these experiments. The results were similar with and without ARNT cotransfection (Appendix 3), so it is reasonable to infer 
that ARNT cotransfection is not required for AHR-based luciferase assays while using the $\mathrm{C} 35$ cell line. It is important to note that this assay only correlates to AHR activation and does not assess binding affinity. This means that the mutation in question may or may not increase binding affinity to PCB 126 , but the results are not determinative of this question.

Luciferase reporter gene assays assessing activation of the SaAHR1 double mutants R310C/A359S and L342M/A359S were also conducted (Appendix 4). These results were not included in this paper due to very low raw luminescence readings for both the induced firefly luciferase as well as the constitutive Renilla luciferase (Appendix 5). This could be due to low transfection efficiency of the luciferase encoding plasmids in these experiments. Because some of the luciferase assay experiments seemed unreliable, we switched from expression in the C35 cell line to expression in the COS7 cell line. Epifluorescence microscopy experiments and western blotting were utilized to confirm adequate expression of the pDEST53SaAHR constructs in the COS7 cell line.

Interestingly and quite unexpectedly, the pDEST53 eGFP-SaAHR1 fusion proteins (wildtype and mutants) are localized in the nucleus when visualized via epifluorescence microscopy (Figure 13). This localization occurred in both PCB 126 dosed wells and vehicle-only control wells for most of the pDEST53 eGFP-SaAHR1 fusion proteins, with the exception of the SaAHR1 P380L mutant (Figure 13). The P380L mutation may have changed the shape of the protein enough to retain it in the cytoplasm, or this result could simply be due to low transfection efficiency. Most characterized AHR isoforms exhibit cytoplasmic localization and only translocate to the nucleus upon 
binding with an agonist. The aberrant localization seen in the epifluorescence microscopy images may be due to the proximity of the eGFP to the AHR's N-terminal nuclear localization sequence. In order to test this, the C-terminal SaAHR1-eGFP fusion protein (which was already created in the Merson Lab, pDEST47SaAHR1) should be tested alongside the pDEST53SaAHR1 construct in a nuclear localization assay. If the Cterminal SaAHR1-eGFP fusion protein revealed similar results to the N-terminal eGFPSaAHR1 fusion protein, this abnormal localization could be due to the SaAHR1 evolving a different function than most vertebrate AHRs. Another experiment that may change this localization would involve co-transfecting AHR chaperones, such as ARA9, in order to preserve the three-dimensional fold of SaAHR1, which may keep the NLS hidden from cellular machinery prior to ligand-binding. Another possibility regarding the localization of the eGFP-AHR fusion proteins could involve unknown endogenous ligands being present in the medium or in the COS7 cell line.

There are many ways to further probe the structure/function characteristics of SaAHR1. One such way would be to create a chimeric protein substituting domains of the DLC-binding SaAHR proteins, perhaps first concentrating on a chimeric SaAHR1 with an SaAHR2 LBD and a chimeric SaAHR1 with a SaAHR2 transactivation domain (TAD). This would allow us to determine whether SaAHR1 can be a functioning transcription factor even if the LBD is changed to the point of restoring agonist binding. Other labs have deleted the entire LBD of mouse AHR, which prevents binding to the chaperone HSP90, and ultimately causes "a ligand-independent constitutively active AHR" $" 55$. 
If it is determined that the SaAHR1 chimera containing the SaAHR2 LBD does not activate DREs, it would be interesting to test the library of mutant constructs created during the course of this study in ligand-binding assays. This would allow the binding affinities to be measured independent of any activation-induced gene transcription events. Ultimately, we may find that the SaAHR1 has evolved a different function than other AHRs, but further experimentation will be needed to make this determination. 


\section{Acknowledgments}

Research reported in this thesis was supported in part by the Institutional Development Award (IDeA) Network for Biomedical Research Excellence from the National Institute of General Medical Sciences of the National Institutes of Health under grant number P20GM103430 through an investigator subaward to Dr. Rebeka Merson, and Rhode Island NSF Established Program to Stimulate Competitive Research (EPSCoR) Genomics and Sequencing Center, supported in part by the National Science Foundation EPSCoR Cooperative Agreement OIA-1655221.

Special thanks to Dr. Michael Denison (University of California, Davis) for the pGudLuc 6.1 plasmid, Dr. Mark Hahn (Woods Hole Oceanographic Institution) for the FhAHR2 and FhARNT2 plasmids, and Dr. Dario Corrada and Dr. Laura Bonati (University of Milano-Bicocca) for the collaboration that provided mutation recommendations.

Thank you to Dr. Rebeka Merson, for teaching me how to conduct scientific research in a laboratory and for providing me many opportunities that I would have never otherwise had. Thank you to my thesis committee members: Dr. Sibel Karchner, Dr. William Holmes, and Dr. Mary Baker. Thank you to Dr. Lloyd Matsumoto for inspiring me to become a biologist during his Biology 111 introductory class. And last, but certainly not least, thank you to my wife Anna Bock, for always believing in me and being the best partner imaginable. 


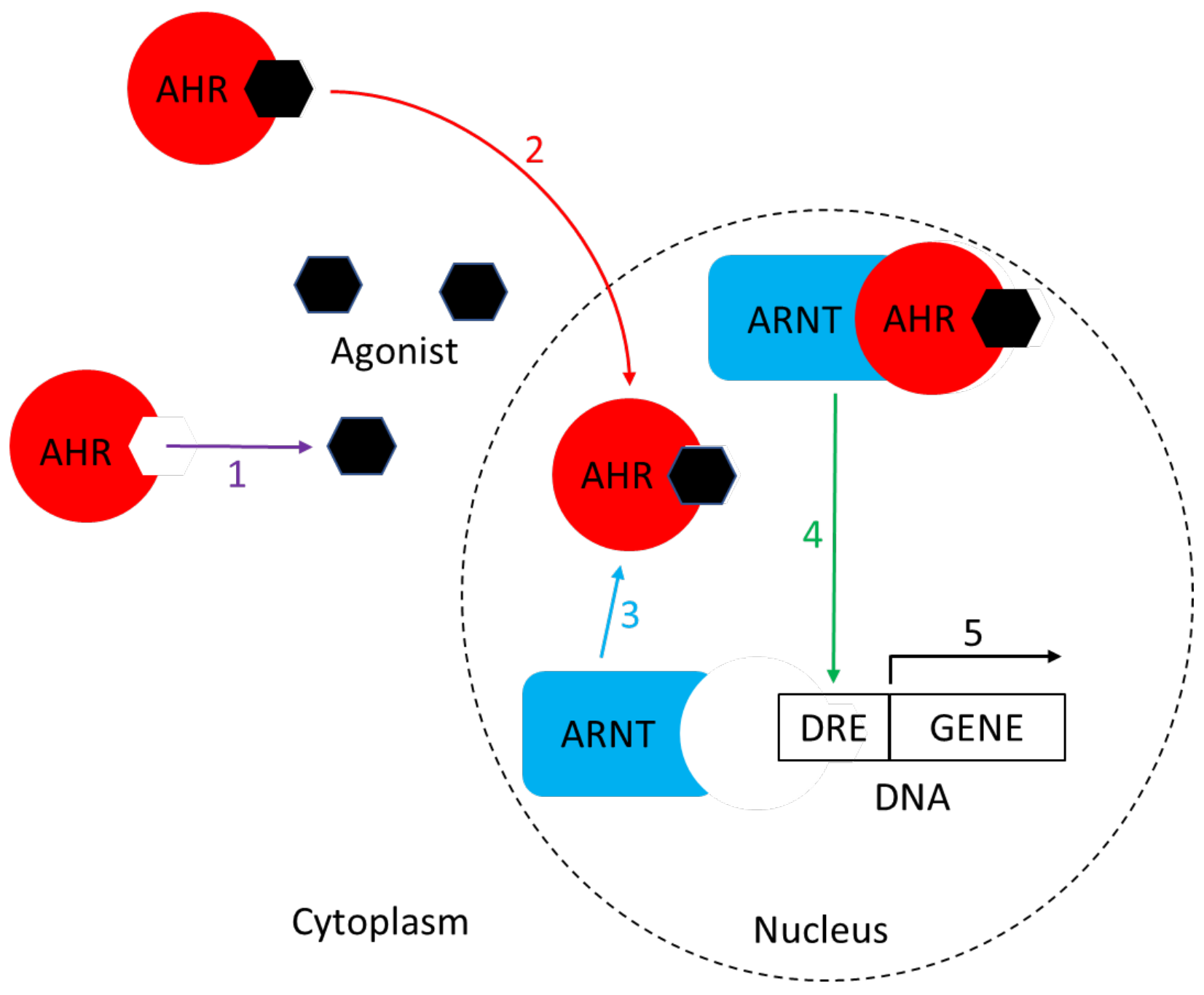

Figure 1: AHR is a ligand-activated transcription factor. (1) AHR binds agonist, (2) AHR translocates into nucleus, (3) ARNT dimerizes with AHR, (4) AHR:ARNT transcription factor complex binds to DREs on DNA, (5) genes under control of DREs are transcribed. 


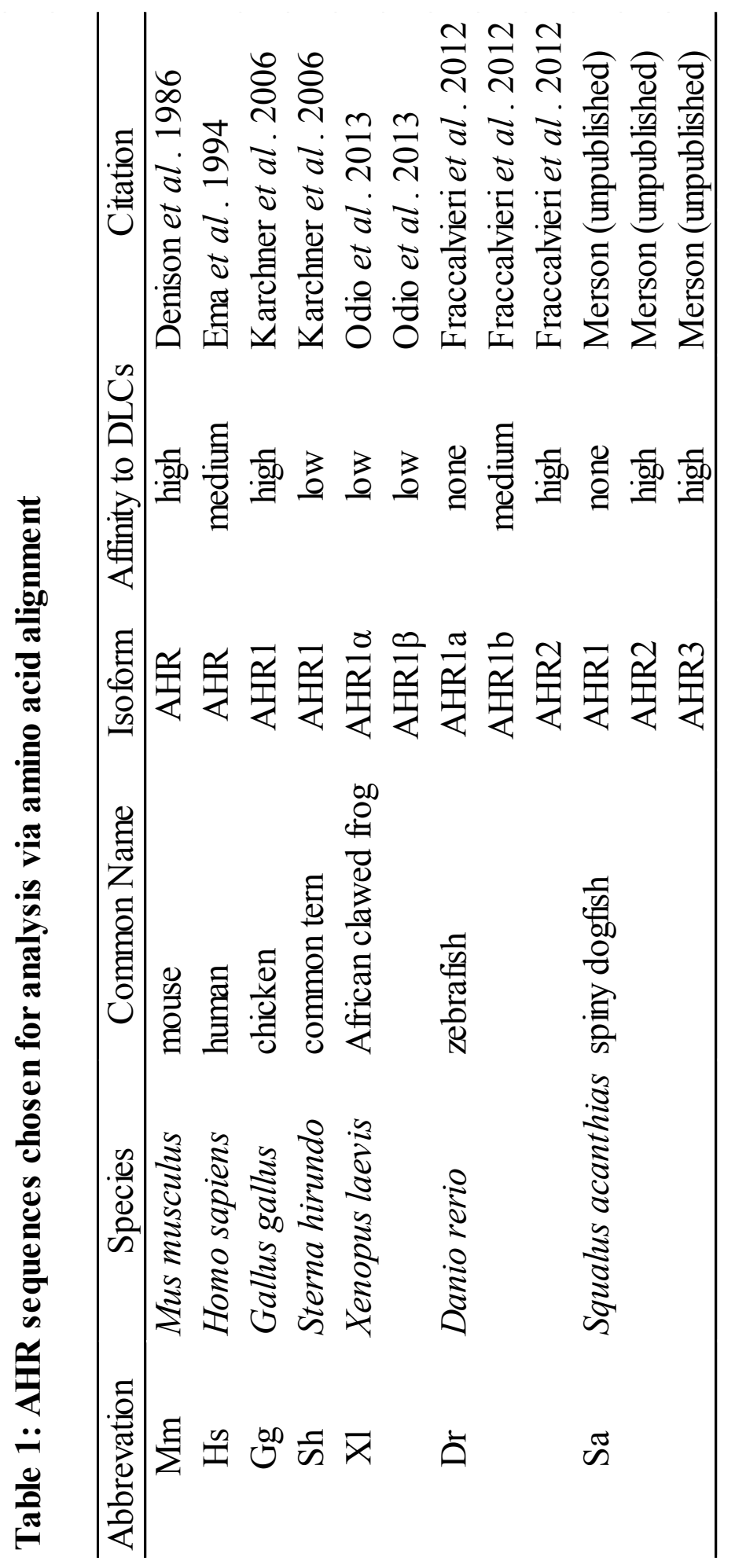




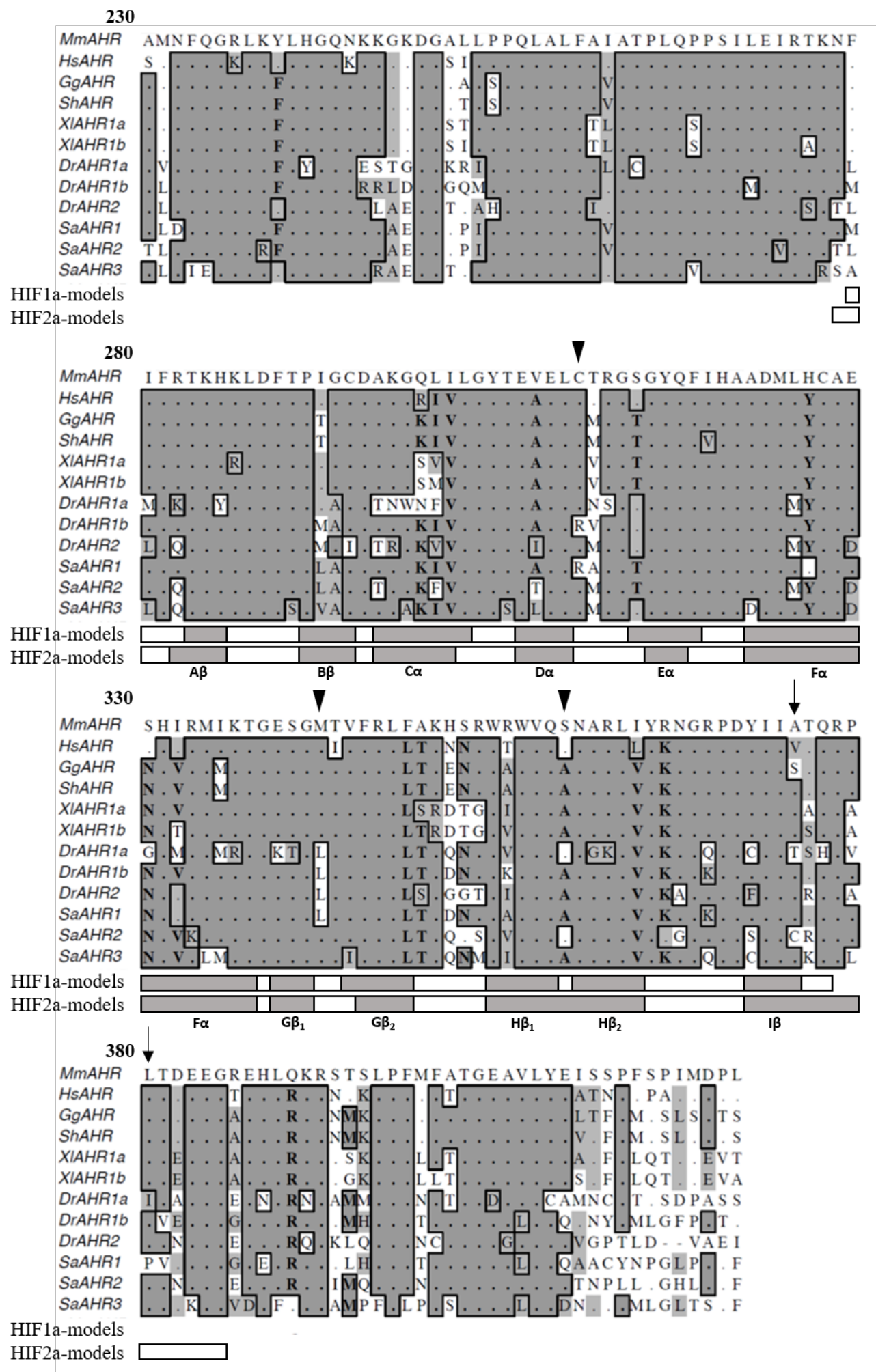

Figure 2: Amino acid alignment of AHR LBDs. Numbering conforms to full length mouse AHR amino acid sequence. Triangles denote mutations recommended by the Bonati Laboratory (R310C, L342M, and A359S) and arrows denote mutations determined by my analysis of homology models (A375C and P380L). Species abbreviations available in Table 1. Modelled area and secondary structures of models noted. 


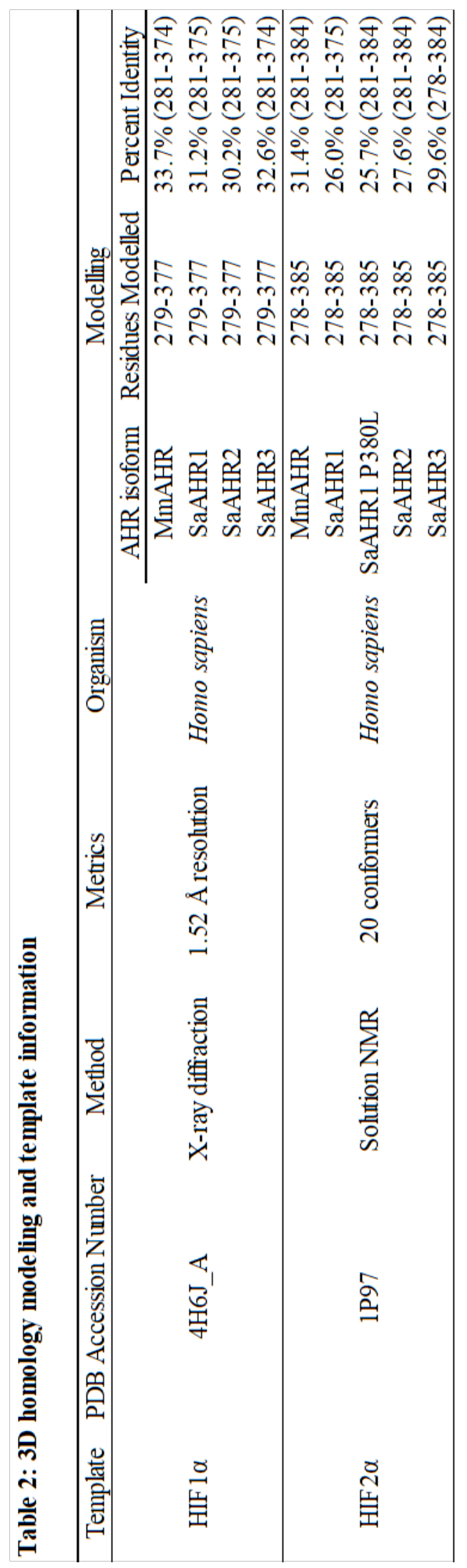




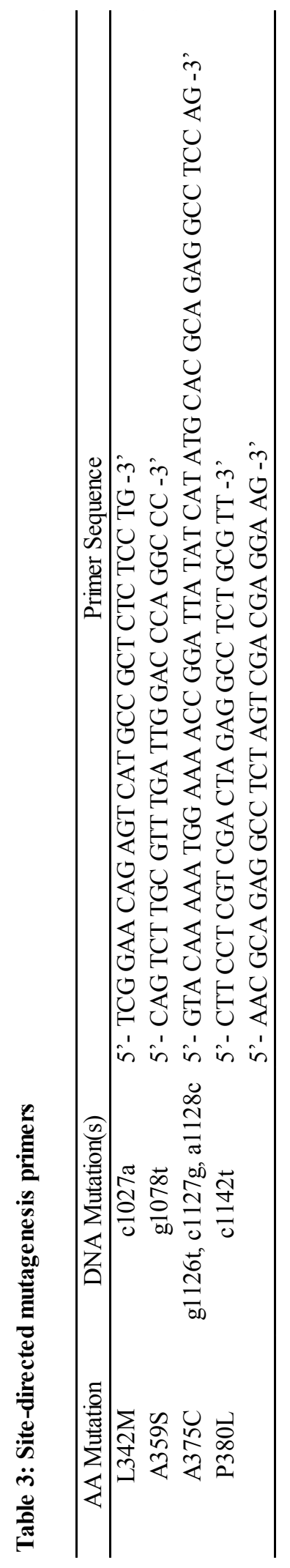



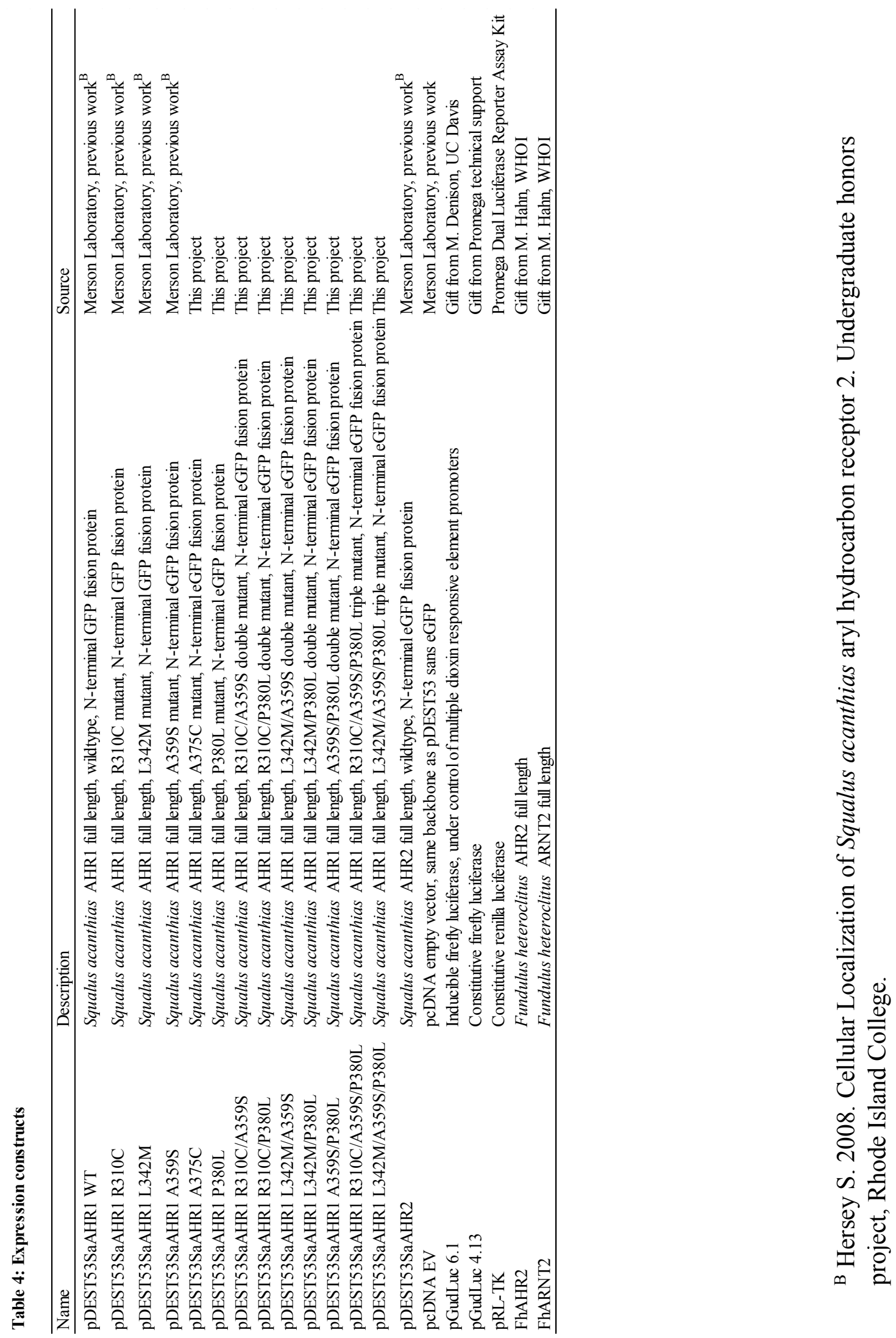
Table 5: Thermal cycling parameters

\begin{tabular}{lccc}
\hline Segment & Cycles & Temp. $\left({ }^{\circ} \mathrm{C}\right)$ & Time (minutes) \\
\hline Denaturation & 1 & 95 & $2: 00$ \\
Denaturation & 30 & 95 & $0: 20$ \\
Annealing & & 55 & $0: 30$ \\
Extension & & 65 & $4: 30$ \\
Final Extension & 1 & 65 & $5: 00$ \\
\hline
\end{tabular}




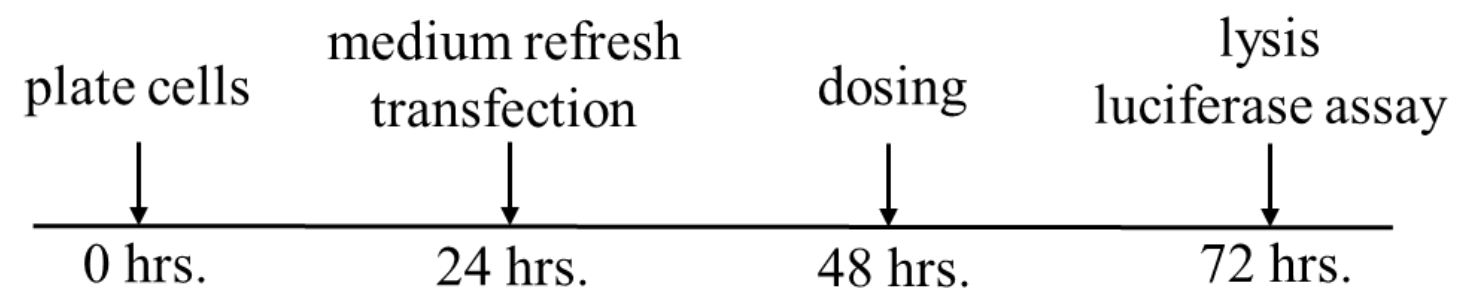

Figure 3: Experimental design for luciferase reporter gene assays. C35 cells were seeded into 48 -well plates at 30,000 cells/well. At $24 \mathrm{hrs}$ post-plating, medium was refreshed and DNA constructs co-transfected with Lipofectamine 2000. At 48 hrs postplating, cells were dosed with either PCB-126 in DMSO (100 nM final concentration) or vehicle-only control. At $72 \mathrm{hrs}$ post-plating, cells were lysed and lysates used for dual luciferase reporter gene assays. 
Table 6: Luciferase assays performed during the course of this study.

\begin{tabular}{|c|c|c|c|c|c|c|}
\hline Assay & Date & Cell type & Transfected plasmids & DNA (ng/well) & Transfection reagent & Objective of experiment \\
\hline \multirow[t]{7}{*}{1} & $2 / 19 / 2015$ & $\mathrm{C} 35$ & pDEST53Sa2 & 50 & Turbofect & Assessment of AHR1 double mutants \\
\hline & & & pDEST53Sa1 WT & 50 & & (R310C/A359S, L342M/A359S). \\
\hline & & & pDEST53Sa1 R310C/A359S & 50 & & \\
\hline & & & pDEST53Sa1 L342M/A359S & 50 & & \\
\hline & & & pGudLuc 6.1 & 20 & & Results shown in Appendix 4, 5 \\
\hline & & & pRL-TK & 3 & & \\
\hline & & & pcDNA empty vector & 50 & & \\
\hline \multirow[t]{7}{*}{2} & $3 / 16 / 2015$ & $\mathrm{C} 35$ & pDEST53Sa2 & 15 & Lipofectamine 2000 & Assessment of AHR1 double mutants \\
\hline & & & pDEST53Sa1 WT & 50 & & (R310C/A359S, L342M/A359S). \\
\hline & & & pDEST53Sa1 R310C/A359S & 50 & & \\
\hline & & & pDEST53Sa1 L342M/A359S & 50 & & \\
\hline & & & pGudLuc 6.1 & 20 & & Results shown in Appendix 4, 5 \\
\hline & & & pRL-TK & 3 & & \\
\hline & & & pcDNA empty vector & 50 & & \\
\hline \multirow[t]{4}{*}{3} & $4 / 10 / 2015$ & $\mathrm{C} 35$ & pDEST53Sa2 & 15 & Lipofectamine 2000 & Optimization of experimental timeline: Dosing 6 \\
\hline & & & pDEST53Sa2 & 30 & & or 24 hours post-transfection. \\
\hline & & & pGudLuc 6.1 & 20 & & \\
\hline & & & pRL-TK & 3 & & Results shown in Appendix 6, 9 \\
\hline \multirow[t]{4}{*}{4} & $4 / 23 / 2015$ & $\mathrm{C} 35$ & pDEST53Sa2 & 15 & Lipofectamine 2000 & Optimization of experimental timeline: Dosing 6 \\
\hline & & & pDEST53Sa2 & 30 & & or 24 hours post-transfection. \\
\hline & & & pGudLuc 6.1 & 20 & & \\
\hline & & & pRL-TK & 3 & & Results shown in Appendix 6, 9 \\
\hline \multirow[t]{7}{*}{5} & $7 / 7 / 2015$ & $\mathrm{C} 35$ & pDEST53 Sa2 & 15 & Lipofectamine 2000 & Assessment of AHR1 with diproline segment \\
\hline & & & pDEST53 Sa1 WT & 50 & & reverted to P-L. \\
\hline & & & pDEST53 Sa1 P380L & 50 & & \\
\hline & & & pGudLuc 4.13 & 50 & & \\
\hline & & & pGudLuc 6.1 & 20 & & Results shown in Appendix 3, 7 \\
\hline & & & pRL-TK & 3 & & \\
\hline & & & pcDNA EV & 50 & & \\
\hline \multirow[t]{9}{*}{6} & $7 / 16 / 2015$ & $\mathrm{C} 35$ & pDEST53Sa2 & 15 & Lipofectamine 2000 & Assessment of AHR1 with diproline segment \\
\hline & & & pDEST53Sa1 WT & 50 & & reverted to P-L, with FhARNT2 added to all \\
\hline & & & pDEST53Sa1 P380L & 50 & & wells. \\
\hline & & & FhAHR2 & 20 & & \\
\hline & & & FhARNT2 & 50 & & \\
\hline & & & pGudLuc 4.13 & 50 & & Results shown in Figure 12, Appendix 7 \\
\hline & & & pGudLuc 6.1 & 20 & & \\
\hline & & & pRL-TK & 3 & & \\
\hline & & & pcDNA EV & 50 & & \\
\hline
\end{tabular}



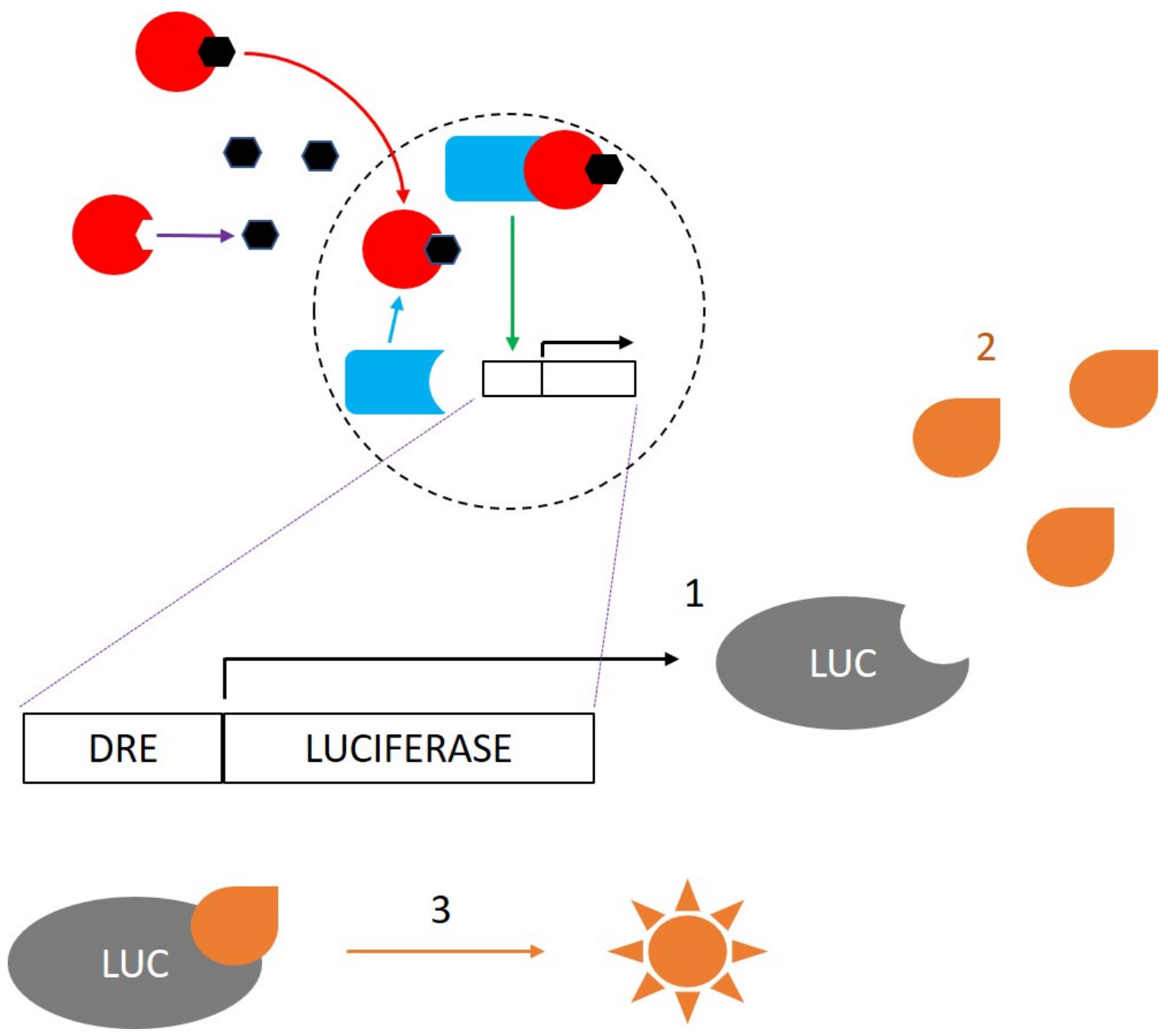

Figure 4: Luciferase reporter gene assay of AHR activation. (1) Activated AHR:ARNT transcription factor complex aids in expression of firefly luciferase, (2) luciferin substrate added to lysates, (3) luciferase catalyzes reaction on substrate, which produces luminescence. 


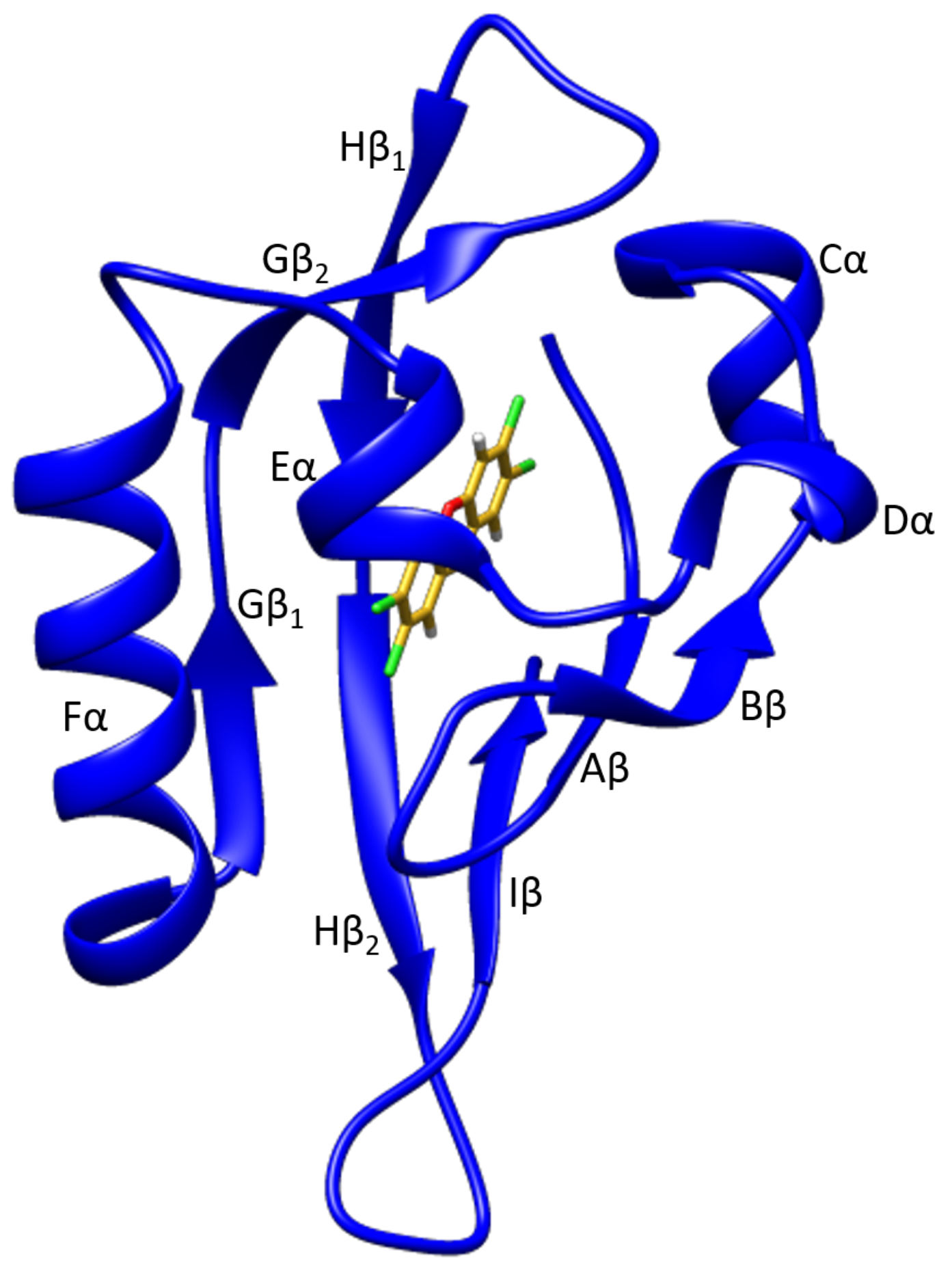

Figure 5: A HIF1a-based 3D model of the SaAHR2 LBD complexed with TCDD. Nomenclature of secondary structure is overlaid. Residues 279-377. 


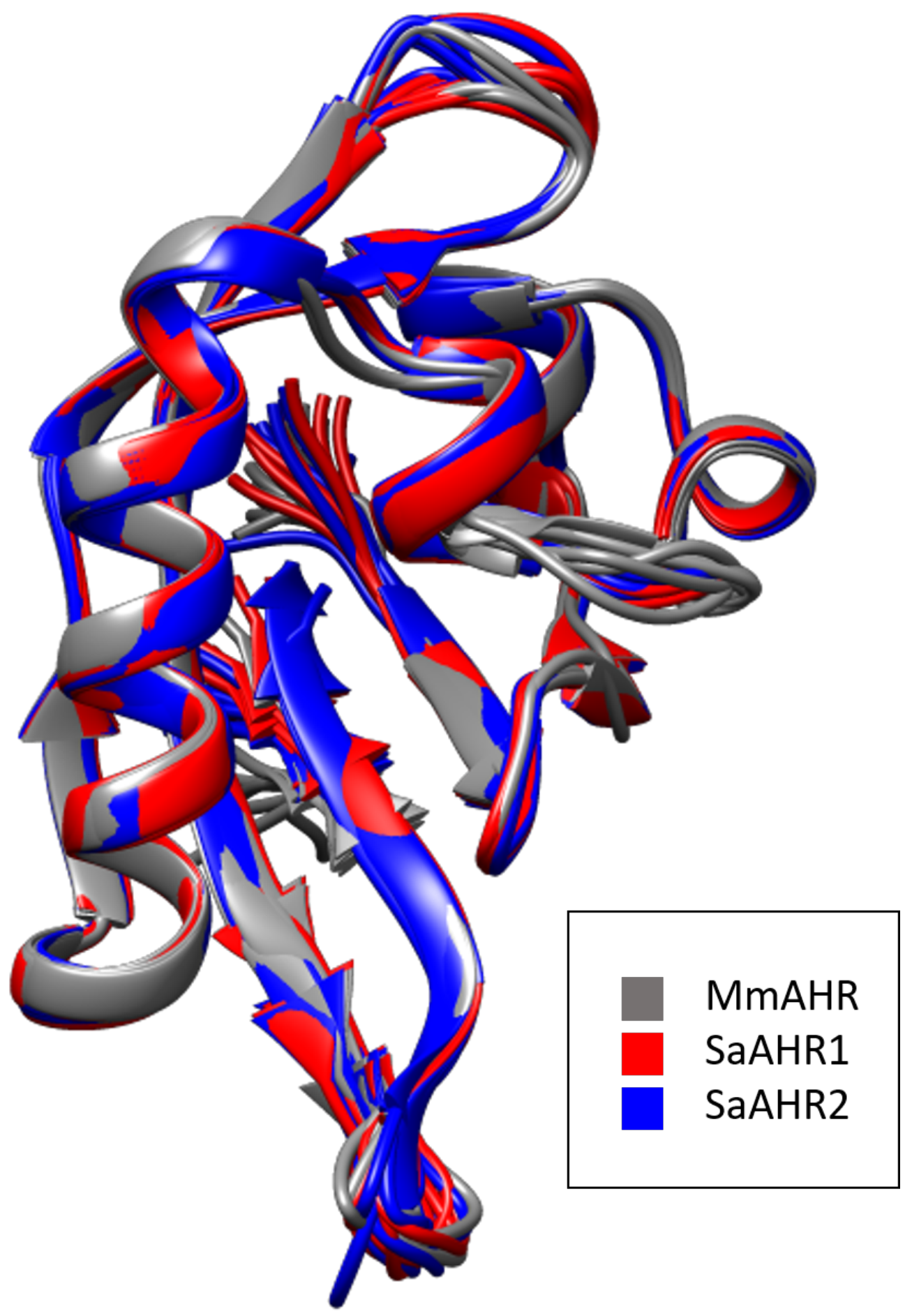

Figure 6: A cluster of HIF1 1 -based AHR models. 10 Models for each MmAHR WT (gray), SaAHR1 WT (red), and SaAHR2 WT (blue). Residues 279-377. 


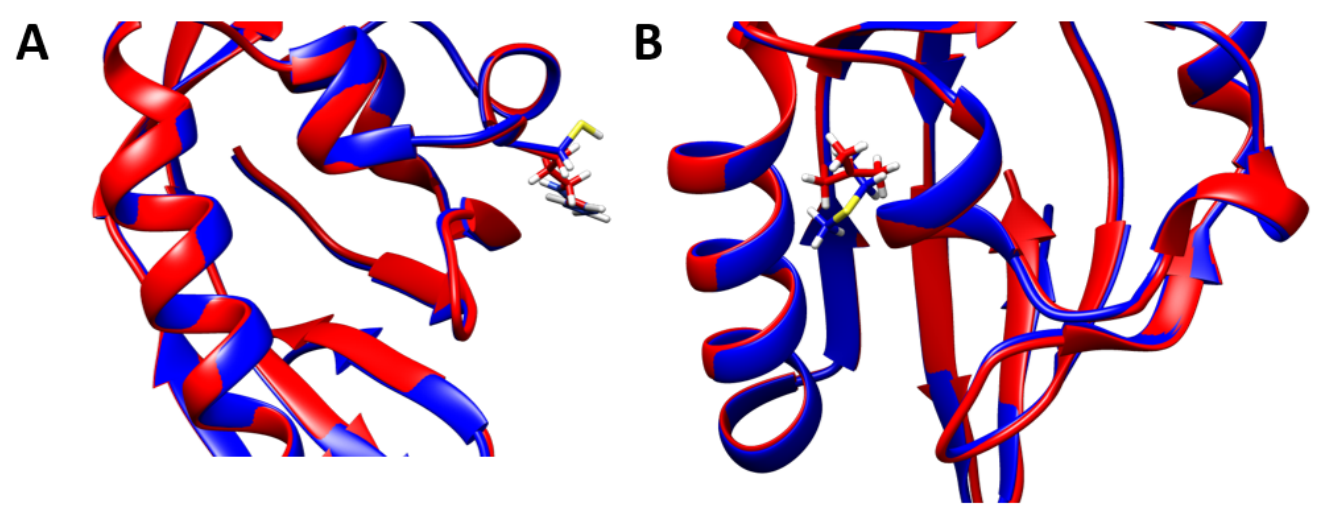

C

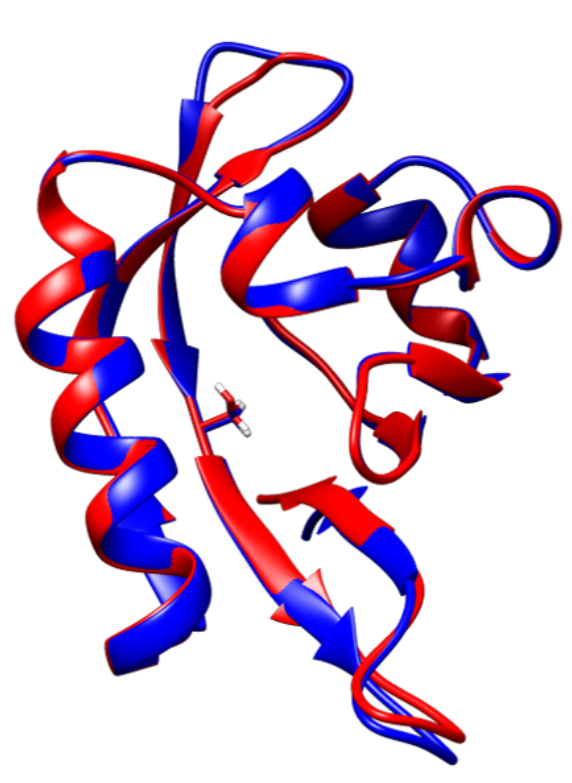

D
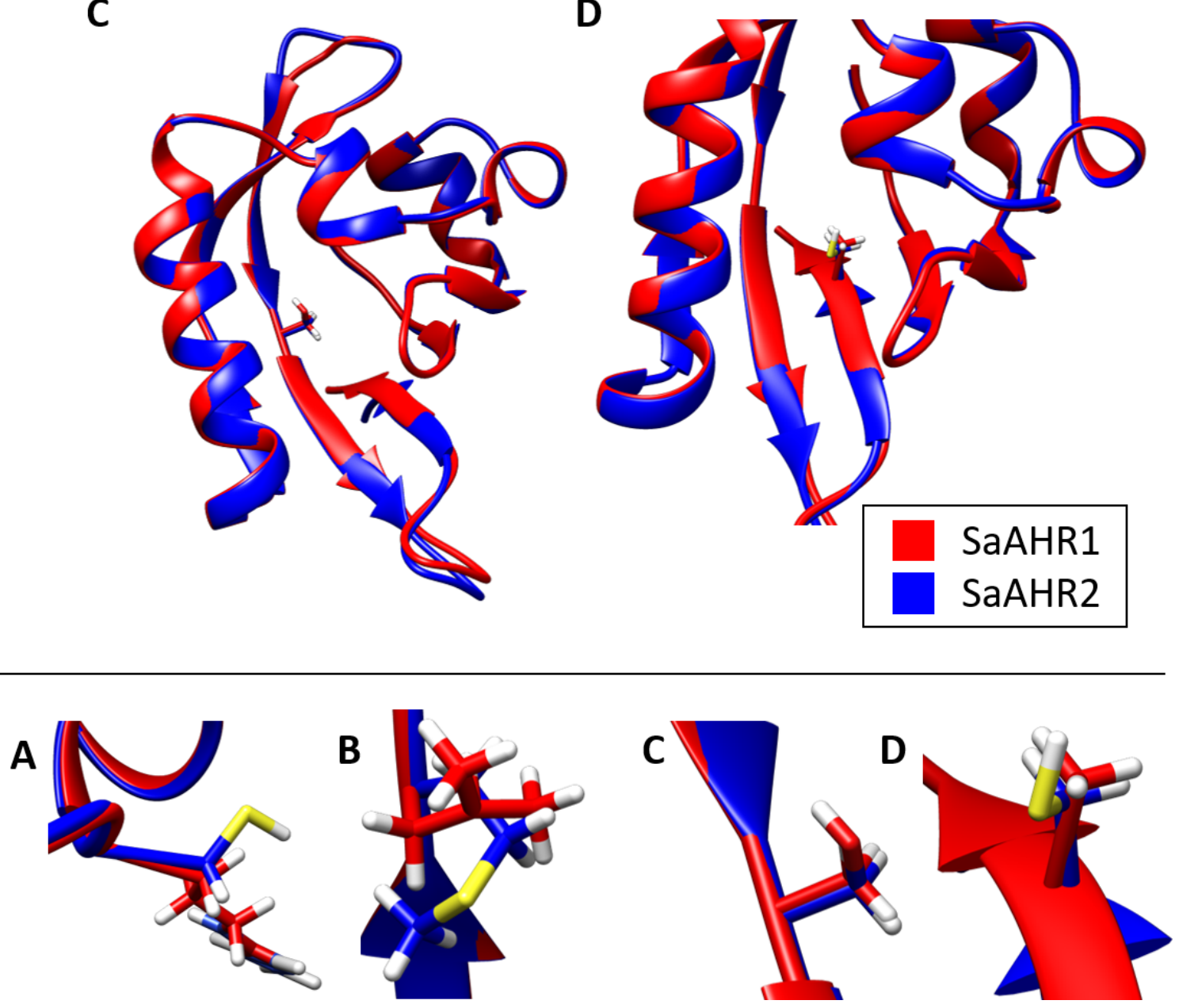

Figure 8: HIF1 $\alpha$-based structural models of SaAHR1 (red) and SaAHR2a (blue): Molecular structure of residues of interest shown (A) R310C, (B) L342M, (C) A359S, (D)A375C. 


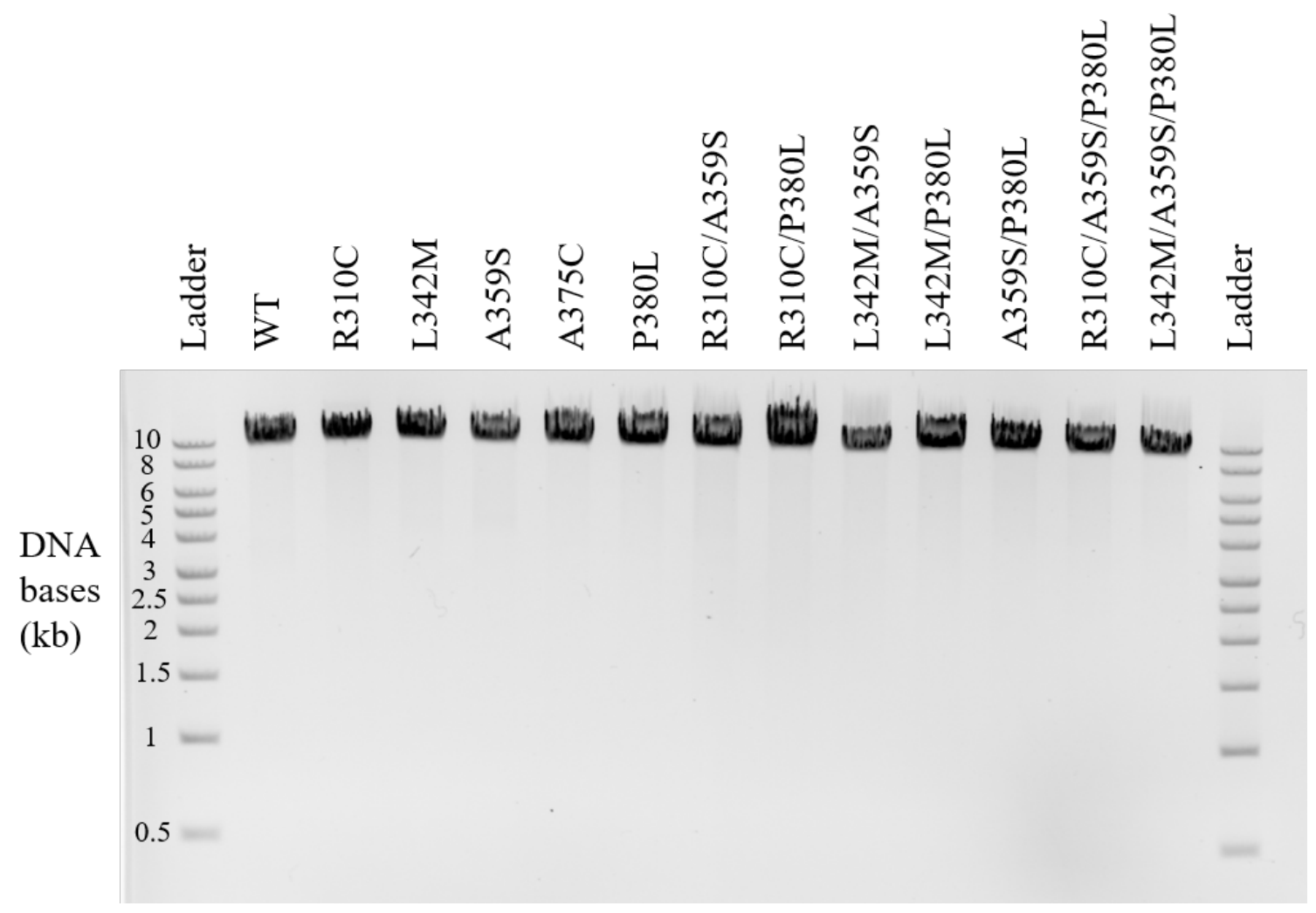

Figure 9: DNA gel electrophoresis of pDEST53SaAHR1 WT and mutant constructs. Mutant constructs are present and consistent in size with wildtype. 

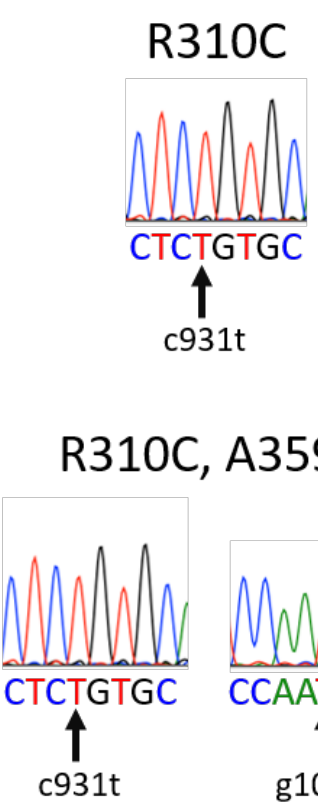

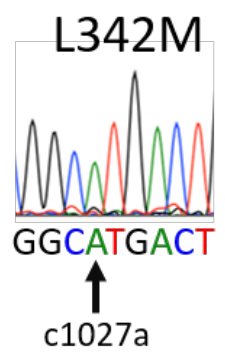

R310C, P380L

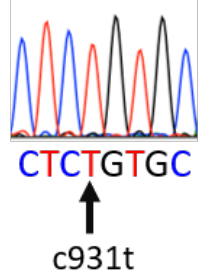

L342M, P380L

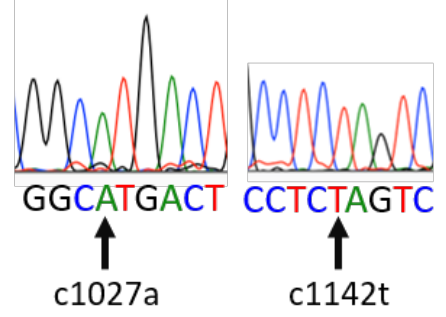

R310C, A359S, P380L

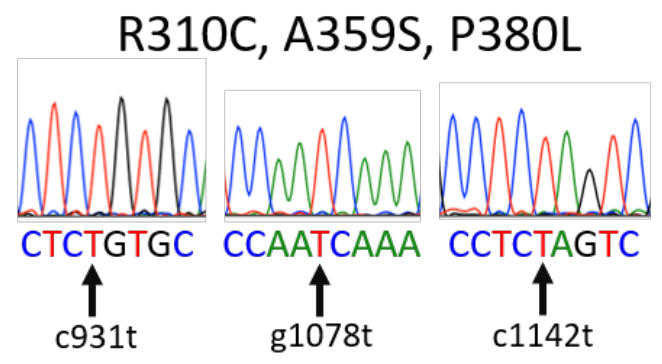

A359S

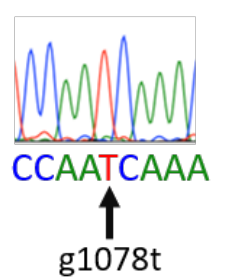

P380L

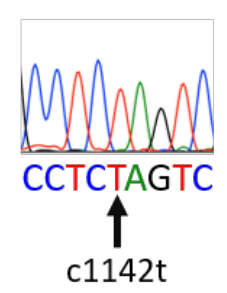

L342M, A359S
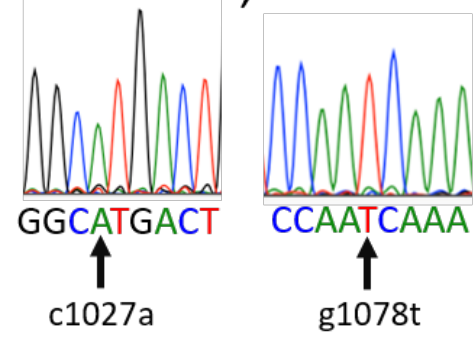

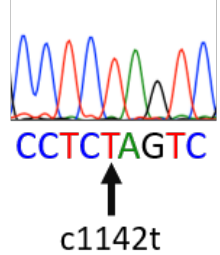

A359S, P380L

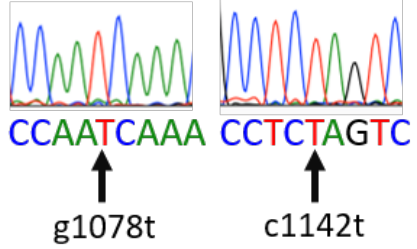

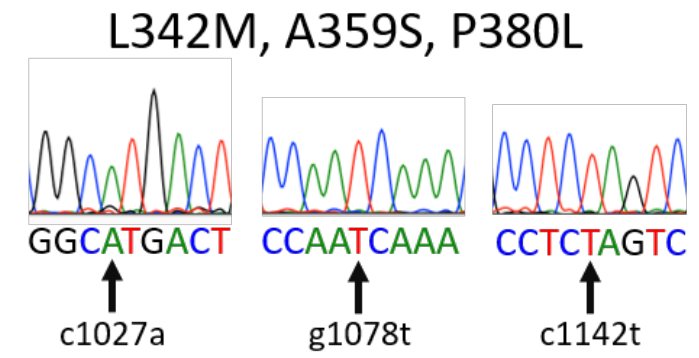

Figure 10: Chromatograms of Sanger sequencing reads show the presence of specified mutations in each mutant DNA construct, with the exception of A375C (no data available). 


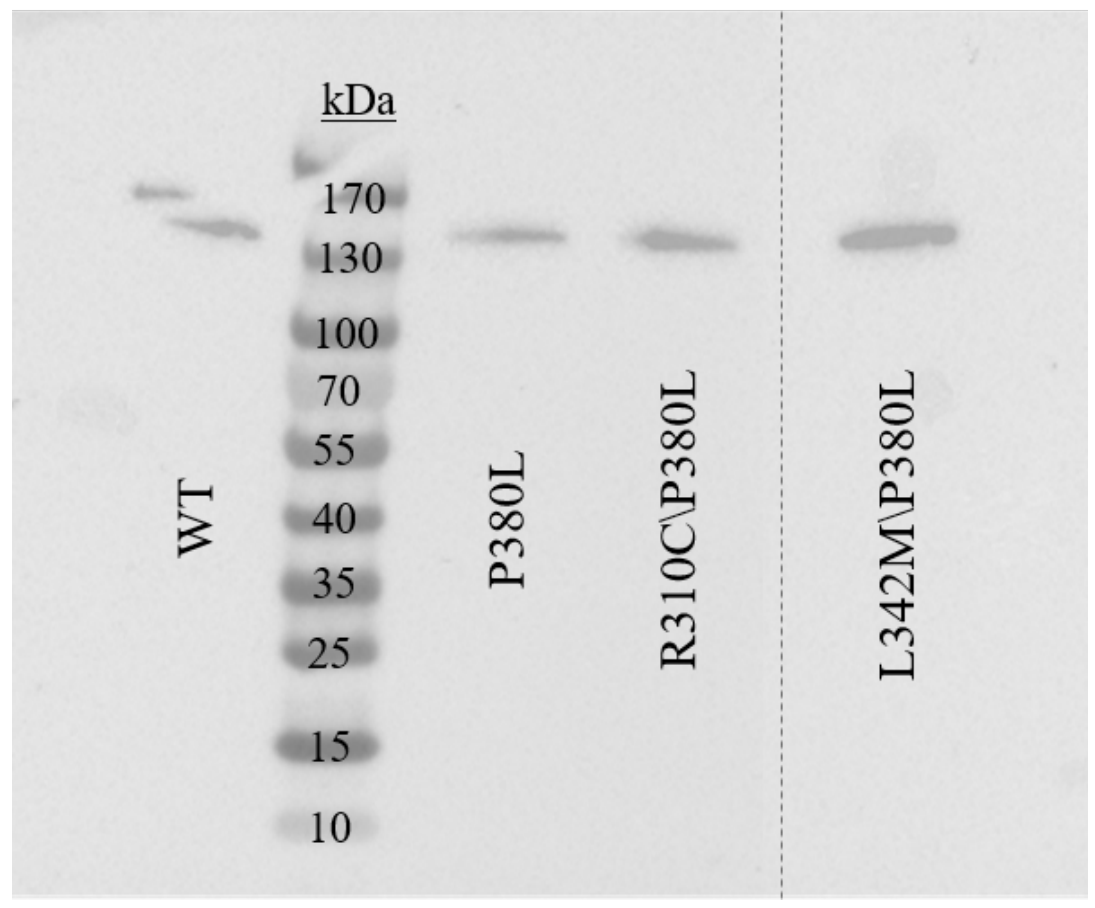

Figure 11: Western blot of pDEST53SaAHR1 WT and mutant constructs show expressed protein with a size consistent with pDEST53SaAHR1 WT calculated size (131.5 kDa). Blotting performed using rabbit anti-GFP-N-terminal primary antibody. Dotted line represents area of blot that was removed in image editing software. 


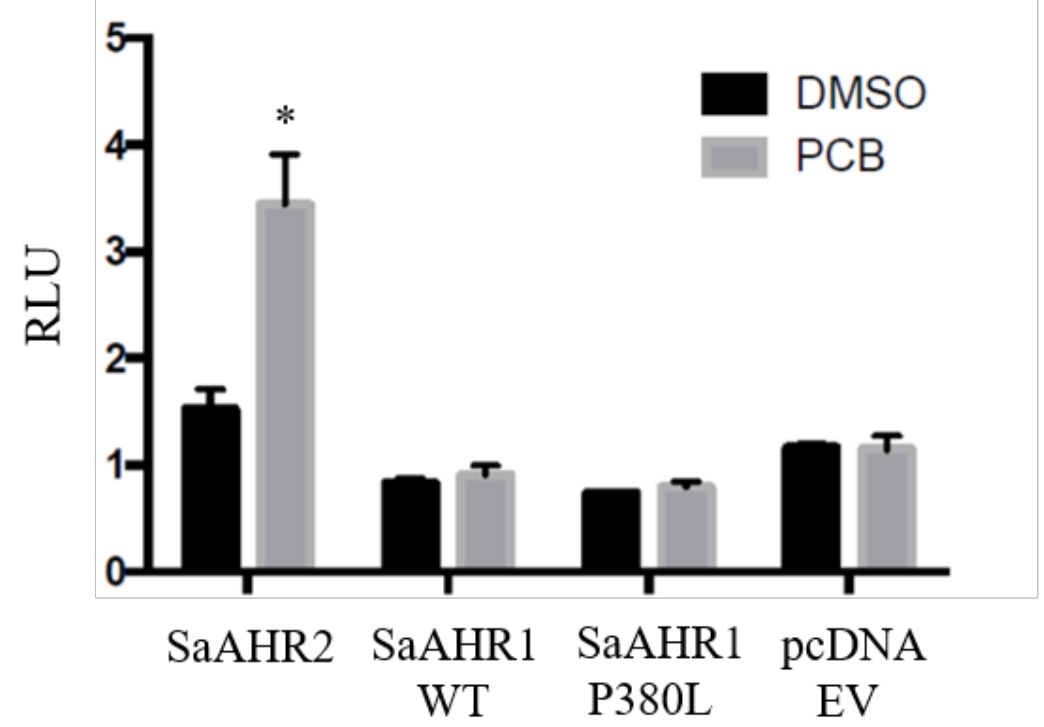

Figure 12: Luciferase assay 6, the P380L mutation did not cause PCB 126 induced activation in dual luciferase reporter gene assay. SaAHR2 was used as a positive control and a pcDNA empty vector was used as a negative control. All replicates were cotransfected with FhARNT2. Bars denote mean value of triplicate wells, error bars denote 1 standard deviation. PCB 126 final concentration of $100 \mathrm{nM}$. Asterisk denotes values significantly different $(\mathrm{P}<0.01)$ from DMSO only control, Student's $t$ test. 

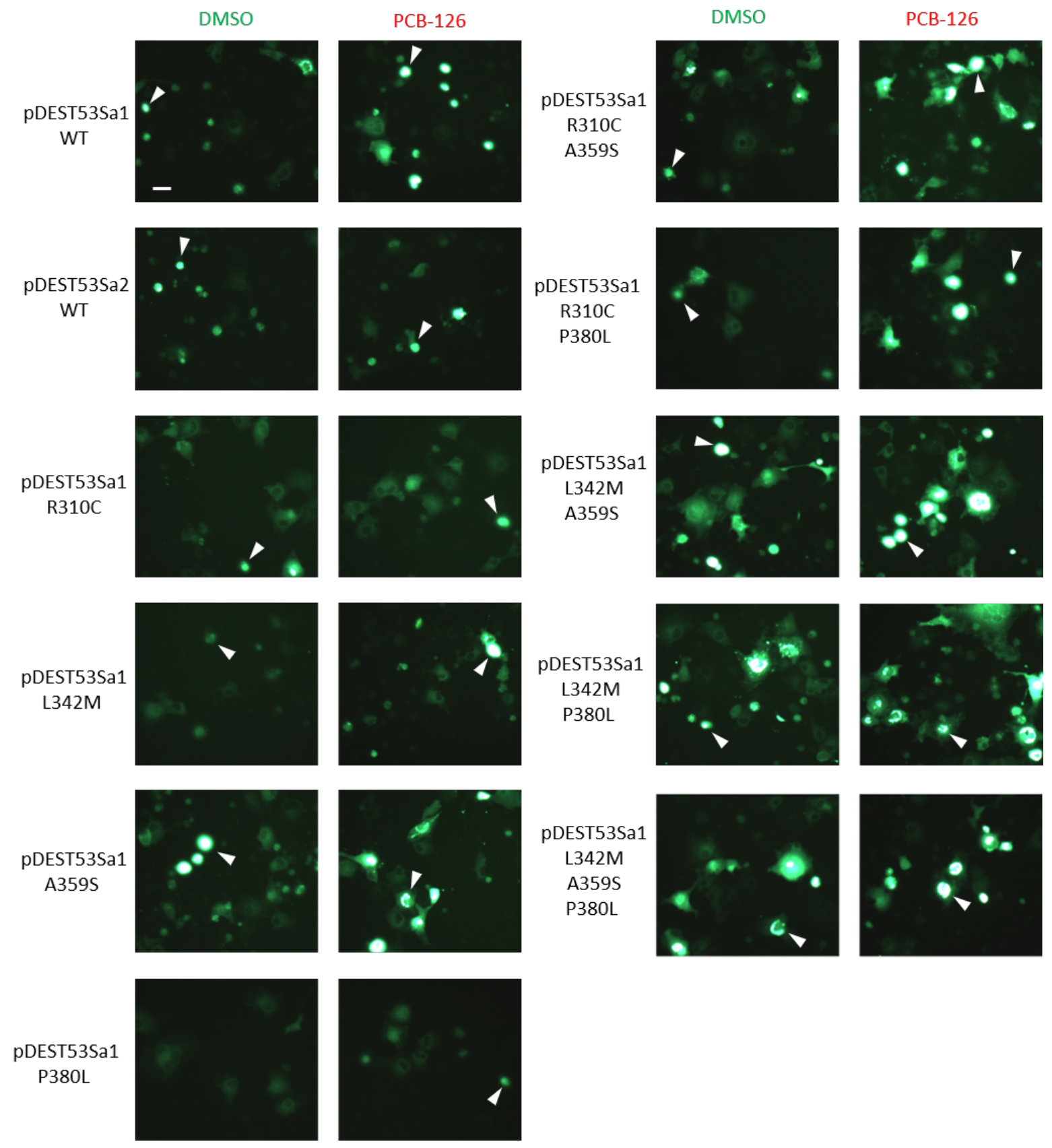

Figure 13: Epifluorescence microscopy (20X objective) of eGFP-AHR-transfected COS7 cellular localization assay. Images were taken 30 hours post dosing $(50 \mathrm{nM}$ final concentration) with either PCB-126 in DMSO or vehicle only. White triangles denote possible nuclear localization. Scale bar in top left image measures $50 \mu \mathrm{m}$. 


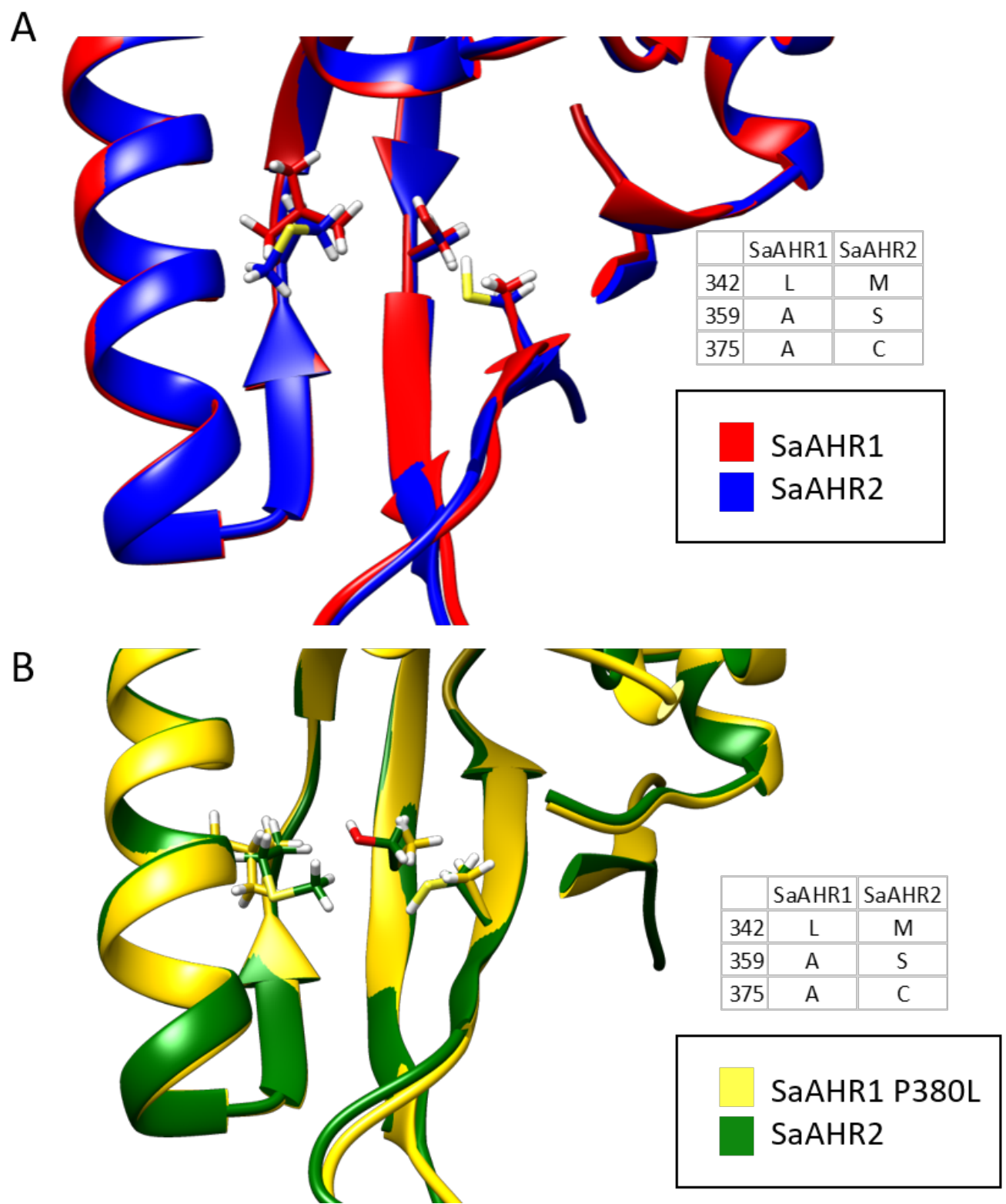

Figure 14: Residues 342, 359, and 375 are adjacent and could form a charged surface for ligand binding. (A) HIF $1 \alpha$-based models, (B) HIF $2 \alpha$-based models. Ribbon positions 284-291 hidden for ease of viewing. 


\section{References}

${ }^{1}$ Walker CH, Sibly RM, Hopkin SP, Peakall DB. 2012. Principles of Ecotoxicology, $4^{\text {th }}$ edition. CRC Press. 360 Pages.

2 Perron MM, Burgess RM, Suuberg EM, Cantwell MG, Pennell KG. 2013. Performance of passive samplers for monitoring estuarine water column concentrations 1.

Contaminants of concern. Environmental Toxicology and Chemistry 32(10): 2182-2189.

${ }^{3}$ Lu Z, Fisk AT, Kovacs KM, Lydersen C, McKinney MA, Tomy GT, Rosenburg B, McMeans BC, Muir DCG, Wong CS. 2014. Temporal and spatial variation in polychlorinated biphenyl chiral signatures of the Greenland shark (Somniosus microcephalus) and its arctic marine food web. Environmental Pollution 186: 216-225.

${ }^{4}$ Hall JE. 2016. Guyton and Hall Textbook of Medical Physiology, 13 ${ }^{\text {th }}$ edition. Elsevier. 1145 pages.

${ }^{5}$ Garrett RH, Grisham CM. 2013. Biochemistry, $5^{\text {th }}$ edition. Cengage Learning. 1169 pages.

${ }^{6}$ Goodman HM. 2009. Basic Medical Endocrinology, $4^{\text {th }}$ edition. Academic Press. 309 Pages.

${ }^{7}$ US EPA. Report on the environment: Greenhouse gas concentrations. Available from https://cfpub.epa.gov/roe/indicator_pdf.cfm?i=24. Accessed July 2019.

${ }^{8}$ Nadal M, Marquès M, Mari M, Domingo JL. 2015. Climate change and environmental concentrations of POPs: A review. Environmental Research 143: 177-185.

${ }^{9}$ World Health Organization. 2016. Dioxins and their effects on human health. Available from https://www.who.int/news-room/fact-sheets/detail/dioxins-and-their-effects-onhuman-health. Accessed May 2019.

${ }^{10}$ US Department of Veteran Affairs. Agent Orange active ingredients and characteristics. Available from https://www.publichealth.va.gov/exposures/agentorange/basics.asp. Accessed July 2019.

${ }^{11}$ Safe S. 1990. Polychlorinated biphenyls (PCBs), dibenzo-p-dioxins (PCDDs), dibenzofurans (PCDFs), and related compounds: Environmental and mechanistic considerations which support the development of toxic equivalency factors (TEFs). Critical Reviews in Toxicology 21(1): 50-88.

12 Pesch C, Voyer R, Latimer J. 2011. Imprint of the past: ecological history of New Bedford Harbor. US EPA.

${ }^{13}$ US EPA. EPA cleanups: Communities around New Bedford Harbor. Available from https://www.epa.gov/new-bedford-harbor. Accessed June 2019. 
${ }^{14}$ Agency for Toxic Substances and Disease Registry. 2014. Polychlorinated biphenyls (PCBs) toxicity. What are polychlorinated biphenyls (PCBs)? Available from https://www.atsdr.cdc.gov/csem/csem.asp?csem=30\&po=4. Accessed March 2019.

15 Burbach KM, Poland A, Bradfield CA. 1992. Cloning of the Ah-receptor cDNA reveals a distinctive ligand-activated transcription factor. Proceedings of the National Academy of Sciences of the United States of America 89: 8185-8189.

${ }^{16}$ Hankinson O. 1995. The aryl hydrocarbon receptor complex. Annual review of pharmacology and toxicology 35: 307-340.

${ }^{17}$ Zhao B, Bohonowych JES, Timme-Laragy A, Jung D, Affatato AA, Rice RH, Di Giulio RT, Denison MS. 2013. Common commercial and consumer products contain activators of the aryl hydrocarbon (dioxin) receptor. PLOS ONE 8(2): e56860.

${ }^{18}$ Zelante T, Iannitti RG, Cunha C, De Luca A, Giovannini G, Pieraccini G, Zecchi R, D’Angelo C, Massi-Benedetti, Fallarino F, Carvalho A. 2013. Tryptophan catabolites from microbiota engage aryl hydrocarbon receptor and balance mucosal reactivity via interleukin-22. Immunity 39: 372-385.

${ }^{19}$ Kewley RJ, Whitelaw ML, Chapman-Smith A. 2004. The mammalian basic-helixloop-helix/PAS family of transcriptional regulators. The International Journal of Biochemistry and Cell Biology 36: 189-204.

${ }^{20}$ Pongratz I, Mason GG, Poellinger L. 1992. Dual roles of the 90-kDa heat shock protein hsp90 in modulating functional activities of the dioxin receptor. The Journal of Biological Chemistry 267(19): 13728-13734.

${ }^{21}$ Meyer BK, Perdew GH. 1999. Characterization of the AhR-hsp90-XAP2 core complex and the role of the immunophilin-related protein XAP2 in AhR stabilization.

Biochemistry 38: 8907-8917.

22 Nguyen PM, Wang D, Wang Y, Li Y, Uchizono JA, Chan WK. 2012. p23 cochaperone protects the aryl hydrocarbon receptor from degradation in mouse and human cell lines. Biochemical Pharmacology 84(6) :838-850.

${ }^{23}$ Denison MS, Fisher JM, Whitlock JP. 1988. The DNA recognition site for the dioxinAh receptor complex. The Journal of Biological Chemistry 263(33): 17221-17224.

24 Tijet N, Boutros PC, Moffat ID, Okey AB, Tuomisto J, Pohjanvirta R. 2006. Aryl hydrocarbon receptor regulates distinct dioxin-dependent and dioxin-independent gene batteries. Molecular Pharmacology 69: 140-153.

${ }^{25}$ Harill JA, Hukkanen RR, Lawson M, Martin B, Gilger B, Soldatow V, LeCluyse EL, Budinsky RA, Rowlands JC, Thomas RS. 2013. Knockout of the aryl hydrocarbon receptor results in distinct hepatic and renal phenotypes in rats and mice. Toxicology and Applied Pharmacology 272: 503-518.

${ }^{26}$ Smith BW, Rozelle SS, Leung A, Ubellacker J, Parks A, Nah SK, French D, Gadue P, Monti S, Chui DHK, Steinberg MH, Frelinger AL, Michelson AD, Theberge R, McComb 
ME, Costello CE, Kotton DN, Mostoslavsky G, Sherr DH, Murphy GJ. 2013. The aryl hydrocarbon receptor directs hematopoietic progenitor cell expansion and differentiation. Blood 122: 376-385.

${ }^{27}$ Hubbard TD, Murray IA, Bisson WH, Lahoti TS, Gowda K, Amin SG, Patterson AD, Perdew GW. 2015. Adaptation of the human aryl hydrocarbon receptor to sense microbiota-derived indoles. Scientific Reports 5: 12689.

${ }^{28}$ Singh NP, Singh UP, Singh B, Price RL, Nagarkatti M, Nagarkatti PS. 2011. Activation of aryl hydrocarbon receptor (AHR) leads to reciprocal epigenetic regulation of FoxP3 and IL-17 expression and amelioration of experimental colitis. PLOS ONE 6(8): e23522.

${ }^{29}$ Hahn, ME. 2002. Aryl hydrocarbon receptors: diversity and evolution. ChemicoBiological Interactions 141: 131 - 160

${ }^{30}$ Hahn ME, Karchner SI, Evans BR, Franks DG, Merson RR, Lapseritis JM. 2006. Unexpected diversity of aryl hydrocarbon receptors in non-mammalian vertebrates: Insights from comparative genomics. Journal of Experimental Zoology 305A: 693-706.

${ }^{31}$ Merson RR, et al. (in prep)

${ }^{32}$ Nebert DW, Dalton TP, Okey AB, Gonzalez FJ. 2004. Role of aryl hydrocarbon receptor-mediated induction of the CYP1 enzymes in environmental toxicity and cancer. The Journal of Biological Chemistry 279(23): 23847-23850.

${ }^{33}$ Walden R, Schiller CM. 1985. Comparative toxicity of 2,3,7,8-tetrachlorodibenzo-pdioxin (TCDD) in four (sub)strains of adult male rats. Toxicology and Applied Pharmacology 77(3): 490-495.

${ }^{34}$ Hahn, ME. 1998. The aryl hydrocarbon receptor: a comparative perspective. Comparative biochemistry and physiology. Part C, Pharmacology, toxicology and endocrinology 121(1-3): 23-53.

${ }^{35}$ Andreasen EA, Tanguay RL, Peterson RE, Heideman W. 2002. Identification of a critical amino acid in the aryl hydrocarbon receptor. The Journal of Biological Chemistry 277(15): 13210-13218.

${ }^{36}$ Pandini A, Denison M, Song Y, Soshilov A, Bonati L. 2006. Structural and functional characterization of the aryl hydrocarbon receptor ligand binding domain by homology modeling and mutational analysis. Biochemistry 46: 696-708.

${ }^{37}$ Denison MS, Soshilov AA, He G, DeGroot DE, Zhao B. 2011. Exactly the same but different: Promiscuity and diversity in the molecular mechanisms of action of the aryl hydrocarbon (dioxin) receptor. Toxicological Sciences 124(1): 1-22.

${ }^{38}$ Fraccalvieri D, Soshilov A, Karchner SI, Franks DG, Pandini A, Bonati L, Hahn ME, Denison MS. 2013. Comparative analysis of homology models of the Ah receptor ligand binding domain: verification of structure-function predictions by site-directed mutagenesis of a nonfunctional receptor. Biochemistry 52: 714-725. 
${ }^{39}$ Odio C, Holzman SA, Denison MS, Fraccalvieri D, Bonati L, Franks DG, Hahn ME, Powell WH. 2013. Specific ligand binding domain residues confer low dioxin responsiveness to AHR1b of Xenopus laevis. Biochemistry 52: 1746-1754.

${ }^{40}$ Mattingly C, Parton A, Dowell L, Rafferty J, Barnes D. 2004. Cell and molecular biology of marine elasmobranchs: Squalus acanthias and Raja erinacea. Zebrafish 1(2): 111-120.

${ }^{41}$ Saha I, Shamala N. 2011. Investigating diproline segments in proteins: occurrences, conformation, and classification. Biopolymers 97(1): 54-64.

${ }^{42}$ Karchner SI, Franks DG, Kennedy SW, Hahn ME. 2006. The molecular basis for differential dioxin sensitivity in birds: Role of the aryl hydrocarbon receptor. PNAS 103(16): 6252-6257.

${ }^{43}$ Larkin MA, Blackshields G, Brown NP, Chenna R, McGettigan PA, McWilliam H, Valentin F, Wallace IM, Wilm A, Lopez R, Thompson JD, Gibson TJ, Higgins DG. 2007. Clustal W and Clustal X version 2.0. Bioinformatics 21: 2947-2948.

${ }^{44}$ Sali A, Blundell TL. 1993. Comparative protein modelling by satisfaction of spatial restraints. Journal of Molecular Biology 234: 779-815.

45 Pettersen EF, Goddard TD, Huang CC, Couch GS, Greenblatt DM, Meng EC, Ferrin TE. 2004. UCSF Chimera - a visualization system for exploratory research and analysis. Journal of Computational Chemistry 25(13): 1605-1612.

${ }^{46}$ Molecular graphics and analyses were performed with the UCSF Chimera package. Chimera is developed by the Resource for Biocomputing, Visualization, and Informatics at the University of California, San Francisco (supported by NIGMS P41-GM103311).

${ }^{47}$ Altschul SF, Gish W, Miller W, Myers EW, Lipman DJ. 1990. Basic local alignment search tool. Journal of Molecular Biology 215: 403-410.

${ }^{48}$ Berman HM, Westbrook J, Feng Z, Gilliland G, Bhat TN, Weissig H, Shindyalov IN, Bourne PE. 2000. The Protein Data Bank. Nucleic Acids Research 28: 235-242.

${ }^{49}$ Cardoso R, Love R, Nilsson CL, Bergqvist S, Nowlin D, Yan J, Liu KK, Zhu J, Chen P, Deng YL, Dyson HJ, Greig MJ, Brooun A. 2012. Identification of Cys255 in HIF-1 $\alpha$ as a novel site for development of covalent inhibitors of HIF-1 $\alpha$ /ARNT PasB domain protein-protein interaction. Protein Science 21(12): 1885-1896.

${ }^{50}$ Erbel PJ, Card PB, Karakuzu O, Bruick RK, Gardner KH. 2003. Structural basis for PAS domain heterodimerization in the basic helix--loop--helix-PAS transcription factor hypoxia-inducible factor. Proceedings of the National Academy of Sciences of the United States of America 100(26): 15504-15509.

${ }^{51}$ Melo F, Sanchez R, Sali A. 2001. Statistical potentials for fold assessment. Protein Science 11: 430-448.

52 Chimera User's Guide. 2015. Comparative modelling. Accessed from https://www.rbvi.ucsf.edu/chimera/docs/UsersGuide/tutorials/dor.html 
53 Shen MY, Sali A. 2006. Statistical potential for assessment and prediction of protein structures. Protein Science 15(11): 2507-2524.

${ }^{54}$ Xing Y, Nukaya M, Satyshur KA, Jiang L, Stanevich V, Korkmaz EN, Burdette L, Kennedy GD, Cui Q, Bradfield CA. 2012. Identification of the Ah-receptor structural determinants for ligand preferences. Toxicological Sciences 129(1): 86-97.

${ }^{55}$ McGuire J, Okamoto K, Whitelaw ML, Tanaka H, Poellinger L. 2001. Definition of a dioxin receptor mutant that is a constitutive activator of transcription: delineation of overlapping repression and ligand binding functions within the PAS domain. The Journal of Biological Chemistry 276: 41841-41849. 
Appendix 1: Raw scores from Modeller results. Bold font denotes one representative model from each isoform.

\begin{tabular}{|c|c|c|c|c|c|c|}
\hline & \multicolumn{3}{|c|}{ HIF1 $\alpha$-based } & \multicolumn{3}{|c|}{ HIF $2 \alpha$-based } \\
\hline Isoform & Model & GA341 & zDOPE & Model & GA341 & zDOPE \\
\hline \multirow{10}{*}{ MmAHR } & 1 & 0.81 & -0.07 & 1 & 0.93 & -0.41 \\
\hline & 2 & 0.70 & 0.00 & 2 & 0.88 & -0.64 \\
\hline & 3 & 0.59 & -0.04 & 3 & 0.82 & -0.47 \\
\hline & 4 & 0.85 & 0.04 & 4 & 0.87 & -0.39 \\
\hline & 5 & 0.87 & -0.03 & 5 & 0.92 & -0.39 \\
\hline & 6 & 0.87 & 0.01 & 6 & 0.81 & -0.48 \\
\hline & 7 & 0.63 & -0.02 & 7 & 0.83 & -0.57 \\
\hline & 8 & 0.91 & -0.10 & 8 & 0.82 & -0.41 \\
\hline & 9 & 0.62 & 0.04 & 9 & 0.86 & -0.65 \\
\hline & 10 & 0.74 & 0.06 & 10 & 0.82 & -0.32 \\
\hline \multirow{10}{*}{ SaAHR1 } & 1 & 0.93 & -0.21 & 1 & 0.92 & -0.03 \\
\hline & 2 & 0.93 & -0.23 & 2 & 0.77 & 0.08 \\
\hline & 3 & 0.76 & -0.45 & 3 & 0.88 & -0.17 \\
\hline & 4 & 0.89 & -0.10 & 4 & 0.91 & -0.10 \\
\hline & 5 & 0.83 & -0.40 & 5 & 0.99 & 0.05 \\
\hline & 6 & 0.90 & -0.37 & 6 & 0.85 & -0.12 \\
\hline & 7 & 0.96 & -0.37 & 7 & 0.79 & -0.07 \\
\hline & 8 & 0.94 & -0.18 & 8 & 0.91 & -0.23 \\
\hline & 9 & 0.86 & -0.01 & 9 & 0.73 & -0.19 \\
\hline & 10 & 0.94 & -0.18 & 10 & 0.90 & -0.17 \\
\hline \multirow{10}{*}{$\begin{array}{c}\text { SaAHR1 } \\
\text { P380L }\end{array}$} & \multirow{3}{*}{\multicolumn{3}{|c|}{ Models not created. }} & 1 & 0.96 & -0.34 \\
\hline & & & & 2 & 0.99 & -0.56 \\
\hline & & & & 3 & 0.85 & -0.39 \\
\hline & \multirow{2}{*}{\multicolumn{3}{|c|}{$\begin{array}{l}\text { Mutation is outside of } \\
\text { modelled area }\end{array}$}} & 4 & 0.80 & -0.50 \\
\hline & & & & 5 & 0.89 & -0.45 \\
\hline & & & & 6 & 0.96 & -0.53 \\
\hline & & & & 7 & 0.95 & -0.46 \\
\hline & & & & 8 & 0.86 & -0.36 \\
\hline & & & & 9 & 0.83 & -0.33 \\
\hline & & & & 10 & 0.93 & -0.48 \\
\hline \multirow{10}{*}{ SaAHR2 } & 1 & 0.54 & -0.15 & 1 & \begin{tabular}{|c|}
0.93 \\
\end{tabular} & \begin{tabular}{|c|}
-0.31 \\
\end{tabular} \\
\hline & 2 & 0.50 & -0.02 & 2 & 0.82 & -0.25 \\
\hline & 3 & 0.55 & -0.06 & 3 & 0.58 & -0.34 \\
\hline & 4 & 0.82 & -0.02 & 4 & 0.81 & -0.29 \\
\hline & 5 & 0.57 & -0.12 & 5 & 0.79 & -0.34 \\
\hline & 6 & 0.58 & 0.00 & 6 & 0.91 & -0.52 \\
\hline & 7 & 0.54 & -0.04 & 7 & 0.72 & -0.48 \\
\hline & 8 & 0.35 & -0.13 & 8 & 0.75 & -0.26 \\
\hline & 9 & 0.79 & -0.06 & 9 & 0.83 & -0.43 \\
\hline & 10 & 0.80 & 0.03 & 10 & 0.74 & -0.45 \\
\hline \multirow{10}{*}{ SaAHR3 } & 1 & 0.85 & 0.14 & 1 & 0.98 & -0.19 \\
\hline & 2 & 0.67 & 0.09 & 2 & 0.77 & -0.42 \\
\hline & 3 & 0.73 & 0.14 & 3 & 0.92 & -0.37 \\
\hline & 4 & 0.71 & 0.16 & 4 & 0.84 & -0.41 \\
\hline & 5 & 0.84 & 0.17 & 5 & 0.93 & -0.32 \\
\hline & 6 & 0.65 & 0.12 & 6 & 0.88 & -0.44 \\
\hline & 7 & 0.84 & -0.08 & 7 & 0.91 & -0.14 \\
\hline & 8 & 0.77 & 0.17 & 8 & 0.95 & -0.25 \\
\hline & 9 & 0.74 & 0.07 & 9 & 0.90 & -0.39 \\
\hline & 10 & 0.58 & 0.08 & 10 & 0.86 & -0.31 \\
\hline
\end{tabular}




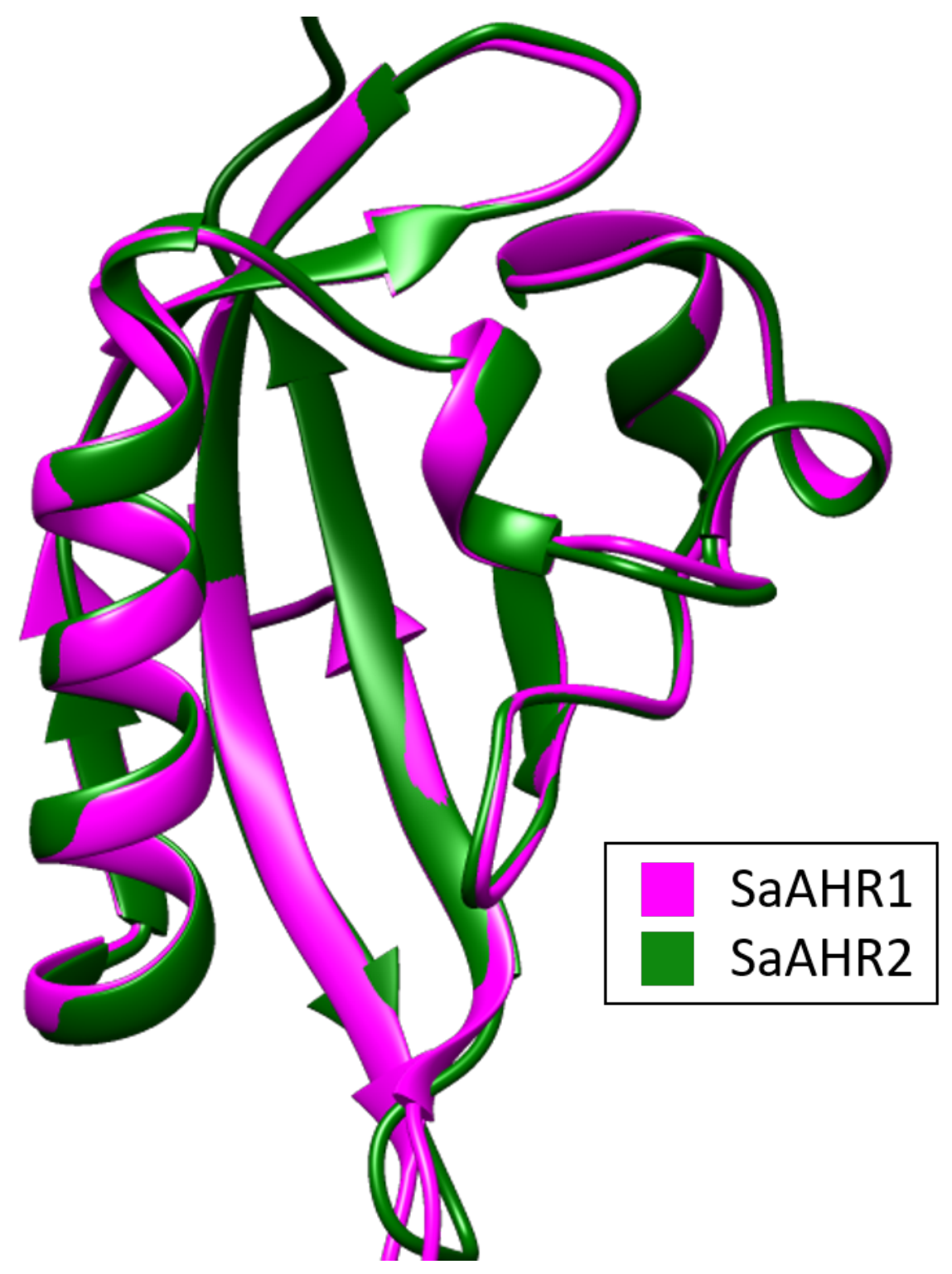

Appendix 2: Representative models of HIF2 $\alpha$-based SaAHR1 WT and SaAHR2 WT. Strand I $\beta$ pulls away from the $\beta$-sheet earlier in the SaAHR1 WT model due to the presence of the diproline motif. 


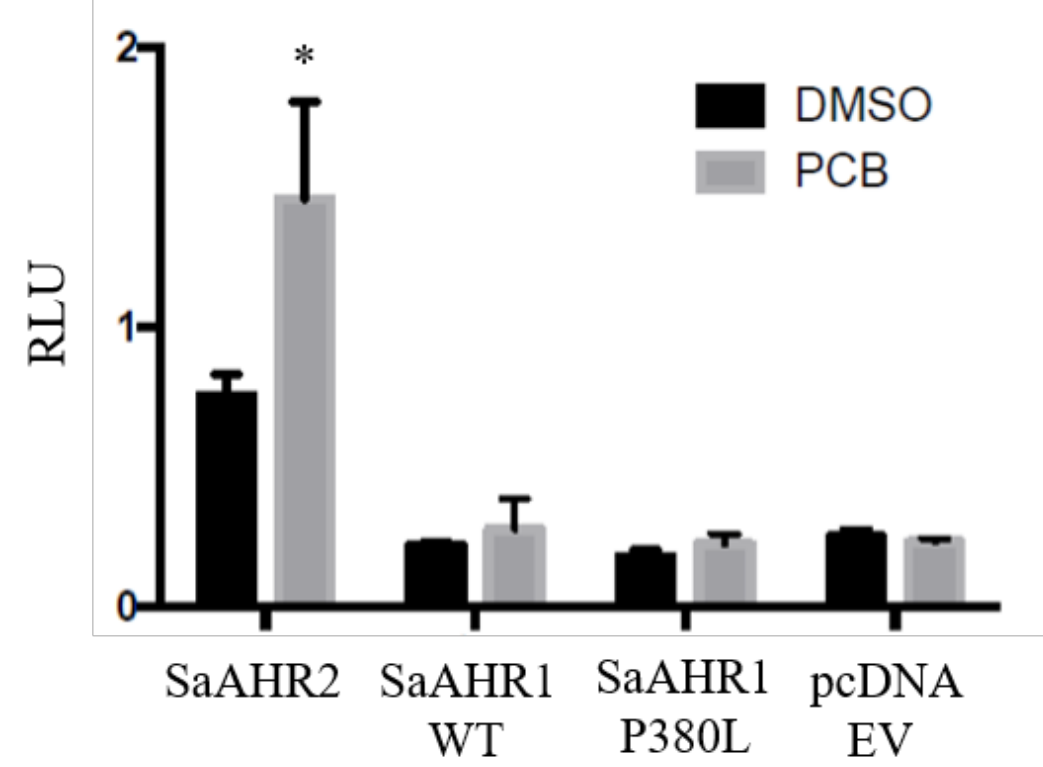

Appendix 3: Luciferase assay 5, the P380L mutation did not cause PCB 126 induced activation in dual luciferase reporter gene assay. SaAHR2 was used as a positive control and a pcDNA empty vector was used as a negative control. This experiment did not include FhARNT2 cotransfection. Bars denote mean value of triplicate wells, error bars denote 1 standard deviation. PCB 126 final concentration of $100 \mathrm{nM}$. Asterisk denotes value significantly different $(\mathrm{P}<0.02)$ from DMSO only control, Student's $t$ test. 

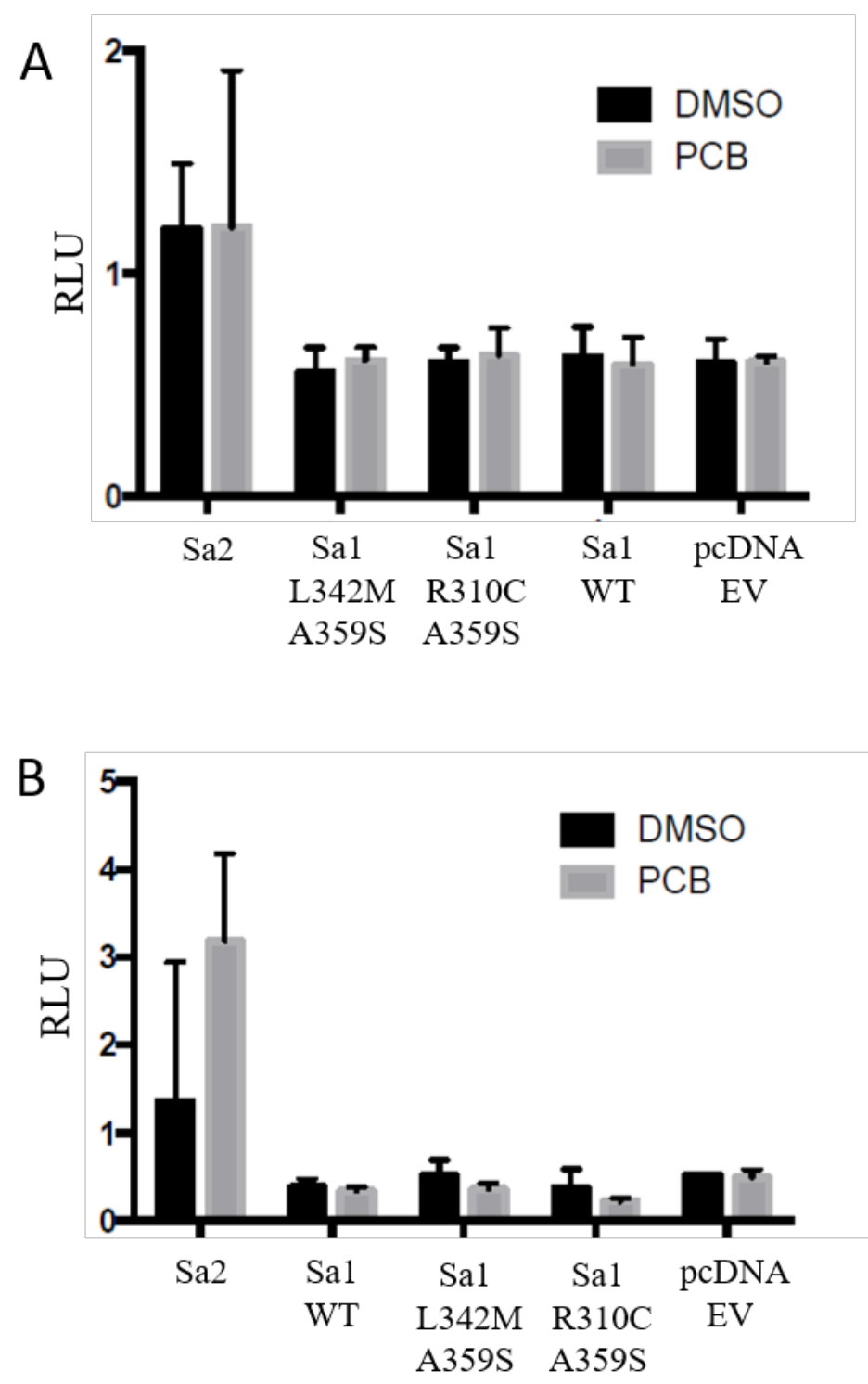

Appendix 4: Luciferase assays 1(A) and 2(B), the L342M/A359S and R310C/A359S double mutants did not cause PCB 126 induced activation in dual luciferase reporter gene assay. These results were not included in the body of this work due to low and possibly unreliable raw luminescence values. SaAHR2 was used as a positive control and a pcDNA empty vector was used as a negative control. This experiment did not include FhARNT2 cotransfection. Bars denote mean value of triplicate wells, error bars denote 1 standard deviation. PCB 126 final concentration of $100 \mathrm{nM}$. 
Appendix 5: Luciferase assay luminescense raw values for assays 1 and 2

\begin{tabular}{|c|c|c|c|c|}
\hline \multicolumn{2}{|c|}{ Assay 1} & firefly & Renilla & RLU \\
\hline \multirow{6}{*}{$\mathrm{Sa} 2$} & \multirow{3}{*}{ DMSO } & 457 & 370 & 1.2344 \\
\hline & & 365 & 247 & 1.476 \\
\hline & & 214 & 239 & 0.8954 \\
\hline & \multirow{3}{*}{ PCB 126} & 810 & 401 & 2.0175 \\
\hline & & 253 & 297 & 0.8524 \\
\hline & & 151 & 201 & 0.7504 \\
\hline \multirow{6}{*}{$\begin{array}{c}\text { Sal } \\
\text { L342M } \\
+ \\
\text { A359S }\end{array}$} & \multirow{3}{*}{ DMSO } & 124 & 218 & 0.5688 \\
\hline & & 120 & 275 & 0.4387 \\
\hline & & 135 & 204 & 0.661 \\
\hline & \multirow{3}{*}{ PCB 126} & 128 & 202 & 0.6333 \\
\hline & & 128 & 196 & 0.6531 \\
\hline & & 117 & 215 & 0.5426 \\
\hline \multirow{6}{*}{$\begin{array}{c}\text { Sal } \\
\text { R310C } \\
+ \\
\text { A359S }\end{array}$} & \multirow{3}{*}{ DMSO } & 118 & 218 & 0.5447 \\
\hline & & 132 & 197 & 0.6726 \\
\hline & & 135 & 229 & 0.5877 \\
\hline & \multirow{3}{*}{ PCB 126} & 188 & 243 & 0.772 \\
\hline & & 121 & 202 & 0.5971 \\
\hline & & 121 & 227 & 0.5347 \\
\hline \multirow{6}{*}{$\begin{array}{l}\text { Sa1 } \\
\text { WT }\end{array}$} & \multirow{3}{*}{ DMSO } & 206 & 404 & 0.5121 \\
\hline & & 244 & 315 & 0.776 \\
\hline & & 147 & 251 & 0.586 \\
\hline & \multirow{3}{*}{ PCB 126} & 150 & 251 & 0.5971 \\
\hline & & 279 & 393 & 0.7102 \\
\hline & & 208 & 444 & 0.4697 \\
\hline \multirow{6}{*}{$\begin{array}{c}\text { pcDNA } \\
\text { EV }\end{array}$} & \multirow{3}{*}{ DMSO } & 143 & 302 & 0.4742 \\
\hline & & 150 & 222 & 0.6746 \\
\hline & & 143 & 222 & 0.6454 \\
\hline & \multirow{3}{*}{ РCB 126} & 149 & 245 & 0.6077 \\
\hline & & 145 & 252 & 0.577 \\
\hline & & 135 & 216 & 0.6244 \\
\hline
\end{tabular}

\begin{tabular}{|c|c|c|c|c|}
\hline \multicolumn{2}{|c|}{ Assay 2} & firefly & Renilla & RLU \\
\hline \multirow{6}{*}{$\mathrm{Sa} 2$} & \multirow{3}{*}{ DMSO } & 158 & 279 & 0.5667 \\
\hline & & 208 & 683 & 0.3051 \\
\hline & & 7201 & 2261 & 3.1846 \\
\hline & \multirow{3}{*}{ PCB 126} & 12162 & 5918 & 2.055 \\
\hline & & 20632 & 5815 & 3.5478 \\
\hline & & 19630 & 4980 & 3.9418 \\
\hline \multirow{6}{*}{$\begin{array}{c}\text { Sal } \\
\text { L342M } \\
+ \\
\text { A359S }\end{array}$} & \multirow{3}{*}{ DMSO } & 210 & 350 & 0.6006 \\
\hline & & 187 & 295 & 0.6337 \\
\hline & & 458 & 1511 & 0.3036 \\
\hline & \multirow{3}{*}{ PCB 126} & 486 & 1636 & 0.2975 \\
\hline & & 604 & 1703 & 0.3548 \\
\hline & & 746 & 1756 & 0.425 \\
\hline \multirow{6}{*}{$\begin{array}{c}\text { Sal } \\
\text { R310C } \\
+ \\
\text { A359S }\end{array}$} & \multirow{3}{*}{ DMSO } & 235 & 1167 & 0.2018 \\
\hline & & 146 & 238 & 0.6144 \\
\hline & & 567 & 1798 & 0.3157 \\
\hline & \multirow{3}{*}{ PCB 126} & 430 & 2102 & 0.2048 \\
\hline & & 366 & 1784 & 0.2054 \\
\hline & & 606 & 2305 & 0.2633 \\
\hline \multirow{6}{*}{$\begin{array}{l}\text { Sa1 } \\
\text { WT }\end{array}$} & \multirow{3}{*}{ DMSO } & 1196 & 4306 & 0.2778 \\
\hline & & 170 & 372 & 0.4574 \\
\hline & & 1553 & 3809 & 0.4078 \\
\hline & \multirow{3}{*}{ PCB 126} & 1771 & 5188 & 0.3414 \\
\hline & & 1494 & 5116 & 0.2921 \\
\hline & & 1504 & 3913 & 0.3845 \\
\hline \multirow{6}{*}{$\begin{array}{c}\text { pcDNA } \\
\text { EV }\end{array}$} & \multirow{3}{*}{ DMSO } & 1245 & 2289 & 0.544 \\
\hline & & 846 & 1650 & 0.513 \\
\hline & & 1986 & 3934 & 0.5049 \\
\hline & \multirow{3}{*}{ PCB 126} & 5149 & 9306 & 0.5533 \\
\hline & & 5003 & 11559 & 0.4328 \\
\hline & & \multicolumn{3}{|c|}{ Third replicate value lost } \\
\hline
\end{tabular}


Appendix 6: Luciferase assay luminescense raw values for assays 3 and 4

\begin{tabular}{|c|c|c|c|c|}
\hline \multicolumn{2}{|c|}{ Assay 3} & firefly & Renilla & RLU \\
\hline \multirow{6}{*}{$\begin{array}{c}\mathrm{Sa} 2 \\
6 \text { hours } \\
15 \text { ng DNA }\end{array}$} & \multirow{3}{*}{ DMSO } & 281 & 1044 & 0.2692 \\
\hline & & 4042 & 846 & 4.7752 \\
\hline & & 278 & 507 & 0.549 \\
\hline & \multirow{3}{*}{ PCB 126} & 131 & 278 & 0.4729 \\
\hline & & 508 & 765 & 0.6641 \\
\hline & & 279 & 742 & 0.3772 \\
\hline \multirow{6}{*}{$\begin{array}{c}\mathrm{Sa} 2 \\
6 \text { hours } \\
30 \text { ng DNA }\end{array}$} & \multirow{3}{*}{ DMSO } & 321 & 539 & 0.5968 \\
\hline & & 420 & 697 & 0.6038 \\
\hline & & 141 & 474 & 0.298 \\
\hline & \multirow{3}{*}{ PCB 126} & 477 & 484 & 0.9864 \\
\hline & & 553 & 606 & 0.9115 \\
\hline & & 1400 & 1054 & 1.3274 \\
\hline \multirow{6}{*}{$\begin{array}{c}\mathrm{Sa} 2 \\
24 \text { hours } \\
15 \text { ng DNA }\end{array}$} & \multirow{3}{*}{ DMSO } & 16335 & 7315 & 2.2331 \\
\hline & & 12957 & 9244 & 1.4017 \\
\hline & & 9675 & 8499 & 1.1384 \\
\hline & \multirow{3}{*}{ PCB 126} & 12247 & 7046 & 1.7382 \\
\hline & & 16965 & 8442 & 2.0096 \\
\hline & & 14245 & 5127 & 2.7783 \\
\hline \multirow{6}{*}{$\begin{array}{c}\mathrm{Sa} 2 \\
24 \text { hours } \\
30 \text { ng DNA }\end{array}$} & \multirow{3}{*}{ DMSO } & 23989 & 8943 & 2.6824 \\
\hline & & 25186 & 7757 & 3.2467 \\
\hline & & 953 & 1288 & 0.7401 \\
\hline & \multirow{3}{*}{ PCB 126} & 6440 & 3084 & 2.0881 \\
\hline & & 15128 & 8673 & 1.7442 \\
\hline & & 28943 & 9165 & 3.1578 \\
\hline
\end{tabular}

\begin{tabular}{|c|c|c|c|c|}
\hline \multicolumn{2}{|c|}{ Assay 4} & firefly & Renilla & RLU \\
\hline \multirow{6}{*}{$\begin{array}{c}\mathrm{Sa} 2 \\
6 \text { hours } \\
15 \text { ng DNA }\end{array}$} & \multirow{3}{*}{ DMSO } & 7400 & 6300 & 1.1746 \\
\hline & & 6205 & 5907 & 1.0505 \\
\hline & & 5224 & 5720 & 0.9133 \\
\hline & \multirow{3}{*}{ PCB 126} & 44086 & 4340 & 10.1564 \\
\hline & & 22721 & 3678 & 6.1763 \\
\hline & & 1222 & 1820 & 0.6713 \\
\hline \multirow{6}{*}{$\begin{array}{c}\mathrm{Sa} 2 \\
6 \text { hours } \\
30 \text { ng DNA }\end{array}$} & \multirow{3}{*}{ DMSO } & 35049 & 12989 & 2.6983 \\
\hline & & 30433 & 12198 & 2.4948 \\
\hline & & 36829 & 12742 & 2.8903 \\
\hline & \multirow{3}{*}{ PCB 126} & 181076 & 15031 & 12.0465 \\
\hline & & 181953 & 15954 & 11.4045 \\
\hline & & 200447 & 13849 & 14.4729 \\
\hline \multirow{6}{*}{$\begin{array}{c}\mathrm{Sa} 2 \\
24 \text { hours } \\
15 \text { ng DNA }\end{array}$} & \multirow{3}{*}{ DMSO } & 3561 & 2275 & 1.5653 \\
\hline & & 58316 & 4739 & 12.3055 \\
\hline & & 14684 & 4581 & 3.2052 \\
\hline & \multirow{3}{*}{ PCB 126} & 15597 & 2476 & 6.2977 \\
\hline & & 65985 & 5706 & 11.5629 \\
\hline & & 11068 & 1251 & 8.8413 \\
\hline \multirow{6}{*}{$\begin{array}{c}\mathrm{Sa} 2 \\
24 \text { hours } \\
30 \text { ng DNA }\end{array}$} & \multirow{3}{*}{ DMSO } & 59953 & 11916 & 5.031 \\
\hline & & 46801 & 9836 & 4.758 \\
\hline & & 84294 & 7779 & 10.8358 \\
\hline & \multirow{3}{*}{ PCB 126} & 323273 & 13075 & 24.7239 \\
\hline & & 240893 & 12530 & 19.2245 \\
\hline & & 266409 & 12291 & 21.6751 \\
\hline
\end{tabular}


Appendix 7: Luciferase assay luminescense raw values for assays 5 and 6

\begin{tabular}{|c|c|c|c|c|}
\hline \multicolumn{2}{|c|}{ Assay 5} & firefly & Renilla & RLU \\
\hline \multirow{6}{*}{$\mathrm{Sa} 2$} & \multirow{3}{*}{ DMSO } & 31977 & 38250 & 0.836 \\
\hline & & 26390 & 38649 & 0.6828 \\
\hline & & 21382 & 28717 & 0.7446 \\
\hline & \multirow{3}{*}{ PCB 126} & 14526 & 13600 & 1.0681 \\
\hline & & 50330 & 28828 & 1.7459 \\
\hline & & 53635 & 34505 & 1.5544 \\
\hline \multirow{6}{*}{$\begin{array}{c}\text { Sa1 } \\
\text { P380L }\end{array}$} & \multirow{3}{*}{ DMSO } & 3828 & 22756 & 0.1683 \\
\hline & & 4947 & 24028 & 0.2059 \\
\hline & & 3625 & 22173 & 0.1635 \\
\hline & \multirow{3}{*}{ PCB 126} & 2926 & 12654 & 0.2312 \\
\hline & & 5476 & 21379 & 0.2562 \\
\hline & & 4902 & 26665 & 0.1839 \\
\hline \multirow{6}{*}{$\begin{array}{l}\text { Sa1 } \\
\text { WT }\end{array}$} & \multirow{3}{*}{ DMSO } & 7691 & 33814 & 0.2275 \\
\hline & & 6533 & 31008 & 0.2107 \\
\hline & & 7947 & 35288 & 0.2252 \\
\hline & \multirow{3}{*}{ РCB 126} & 8633 & 21419 & 0.4031 \\
\hline & & 6001 & 28363 & 0.2116 \\
\hline & & 6308 & 29765 & 0.2119 \\
\hline \multirow{6}{*}{$\begin{array}{l}\text { pGL } \\
4.13\end{array}$} & \multirow{3}{*}{ DMSO } & 20560674 & 13136 & 1565 \\
\hline & & 35686976 & 23896 & 1493 \\
\hline & & 36266048 & 20220 & 1793 \\
\hline & \multirow{3}{*}{ PCB 126} & 5195250 & 6845 & 758.901 \\
\hline & & 34280424 & 20845 & 1644 \\
\hline & & 33775972 & 21542 & 1567 \\
\hline \multirow{6}{*}{$\begin{array}{c}\text { pcDNA } \\
\text { EV }\end{array}$} & \multirow{3}{*}{ DMSO } & 17949 & 80147 & 0.224 \\
\hline & & 15827 & 61235 & 0.2585 \\
\hline & & 19092 & 70299 & 0.2716 \\
\hline & \multirow{3}{*}{ PCB 126} & 10055 & 46166 & 0.2178 \\
\hline & & 15803 & 66438 & 0.2379 \\
\hline & & 15958 & 67104 & 0.2378 \\
\hline \multirow{6}{*}{$\begin{array}{c}\text { COS7 } \\
\text { untransfected } \\
\text { control }\end{array}$} & \multirow{3}{*}{ DMSO } & 295 & 341 & 0.8672 \\
\hline & & 772 & 361 & 2.1364 \\
\hline & & 381 & 341 & 1.1188 \\
\hline & \multirow{3}{*}{ PCB 126} & 203 & 343 & 0.593 \\
\hline & & 207 & 351 & 0.5908 \\
\hline & & 189 & 335 & 0.5652 \\
\hline
\end{tabular}

\begin{tabular}{|c|c|c|c|c|}
\hline \multicolumn{2}{|c|}{ Assay 6} & firefly & Renilla & RLU \\
\hline \multirow{6}{*}{$\mathrm{Sa} 2$} & \multirow{3}{*}{ DMSO } & 88867 & 53236 & 1.6693 \\
\hline & & 115113 & 72995 & 1.577 \\
\hline & & 79749 & 60513 & 1.3179 \\
\hline & \multirow{3}{*}{ PCB 126} & 319767 & 81464 & 3.9253 \\
\hline & & 186850 & 54938 & 3.4011 \\
\hline & & 127319 & 42526 & 2.9939 \\
\hline \multirow{6}{*}{$\begin{array}{c}\text { Sal } \\
\text { P380L }\end{array}$} & \multirow{3}{*}{ DMSO } & 24639 & 34114 & 0.7223 \\
\hline & & 23895 & 31904 & 0.749 \\
\hline & & 29158 & 39675 & 0.7349 \\
\hline & \multirow{3}{*}{ PCB 126} & 32087 & 41349 & 0.776 \\
\hline & & 28402 & 33430 & 0.8496 \\
\hline & & 24144 & 32078 & 0.7527 \\
\hline \multirow{6}{*}{$\begin{array}{l}\text { Sa1 } \\
\text { WT }\end{array}$} & \multirow{3}{*}{ DMSO } & 36203 & 45395 & 0.7975 \\
\hline & & 37184 & 46222 & 0.8045 \\
\hline & & 46174 & 52258 & 0.8836 \\
\hline & \multirow{3}{*}{ PCB 126} & 46953 & 57553 & 0.8158 \\
\hline & & 39106 & 39387 & 0.9929 \\
\hline & & 30432 & 33496 & 0.9085 \\
\hline \multirow{6}{*}{$\begin{array}{l}\text { pGL } \\
4.13\end{array}$} & \multirow{3}{*}{ DMSO } & 153667024 & 58237 & 2638 \\
\hline & & 148657344 & 52085 & 2854 \\
\hline & & 165592592 & 64682 & 2560 \\
\hline & \multirow{3}{*}{ PCB 126} & 170774336 & 65619 & 2602 \\
\hline & & 162415440 & 59972 & 2708 \\
\hline & & 144758880 & 53262 & 2717 \\
\hline \multirow{6}{*}{$\begin{array}{c}\text { pcDNA } \\
\text { EV }\end{array}$} & \multirow{3}{*}{ DMSO } & 120165 & 102773 & 1.1692 \\
\hline & & 81386 & 71168 & 1.1436 \\
\hline & & 111004 & 93026 & 1.1933 \\
\hline & \multirow{3}{*}{ PCB 126} & 140270 & 116439 & 1.2047 \\
\hline & & 74448 & 73613 & 1.0113 \\
\hline & & 83627 & 67479 & 1.2393 \\
\hline \multirow{6}{*}{ FhAHR2 } & \multirow{3}{*}{ DMSO } & 2017297 & 54276 & 37.167 \\
\hline & & 2530627 & 62795 & 40.2992 \\
\hline & & 3068355 & 88995 & 34.4776 \\
\hline & \multirow{3}{*}{ PCB 126} & 3333815 & 66278 & 50.2999 \\
\hline & & 4563634 & 72341 & 63.0842 \\
\hline & & 4105533 & 68834 & 59.6439 \\
\hline
\end{tabular}



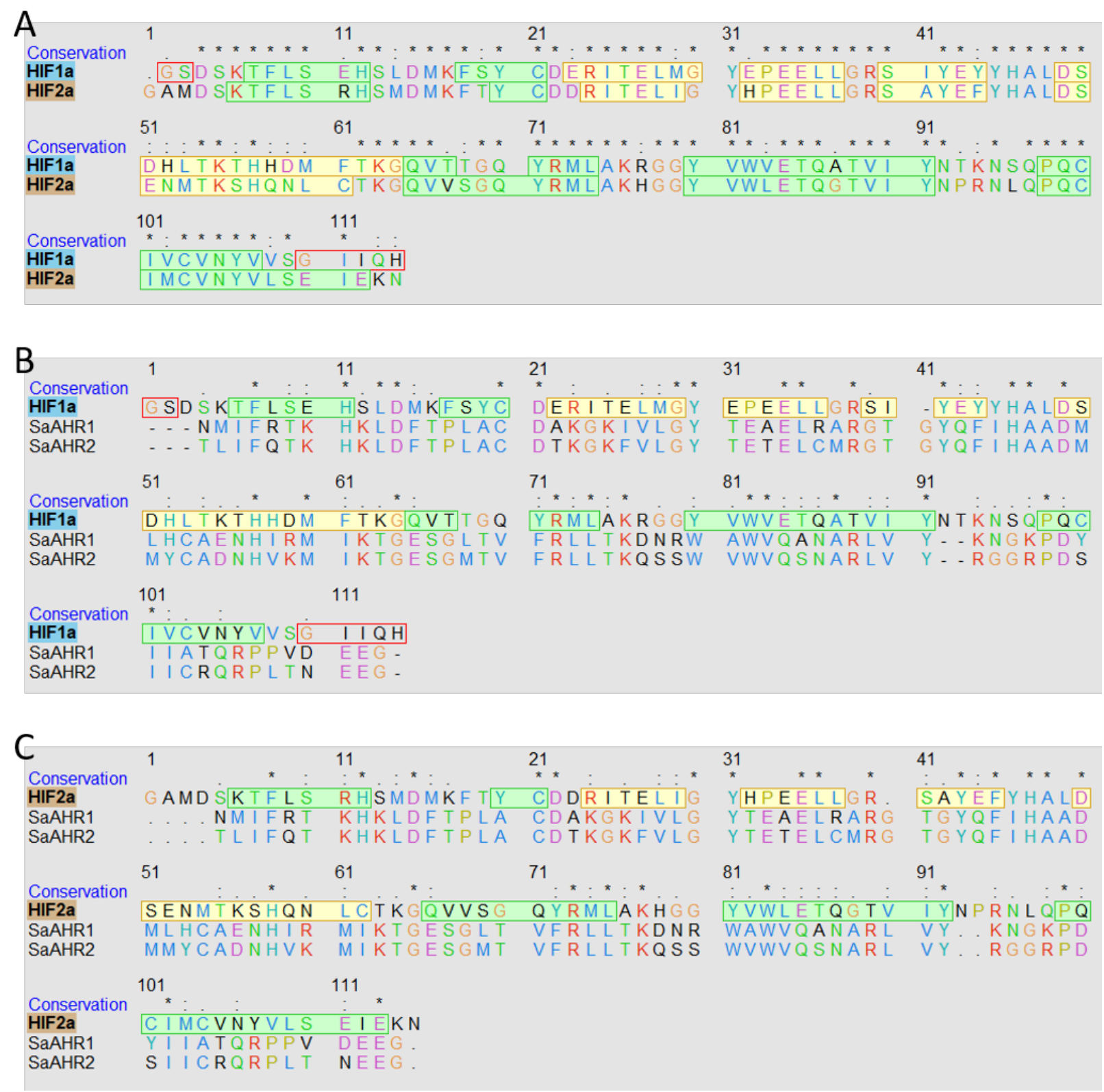

\section{Appendix 8: Alignments of structural templates (HIF1 $\alpha$ and HIF2 $\alpha$ ) vs. model sequence} (SAAHR1 and SaAHR2). Screenshots taken from UCSF Chimera program. Green highlighted sequence denotes $\beta$-strand in structural template. Yellow highlighted sequence denotes $\alpha$-helix in structural template. AHR sequences start at residue 278. Conservation symbols: asterisk denotes homologous residue, colon denotes highly similar residue, period denotes less similar residue. (A) HIF1 $\alpha$ vs. HIF2 $\alpha$, (B) HIF1 $\alpha$ vs. SaAHR1 and SaAHR2, (C) HIF $2 \alpha$ vs. SaAHR1 and SaAHR2. 

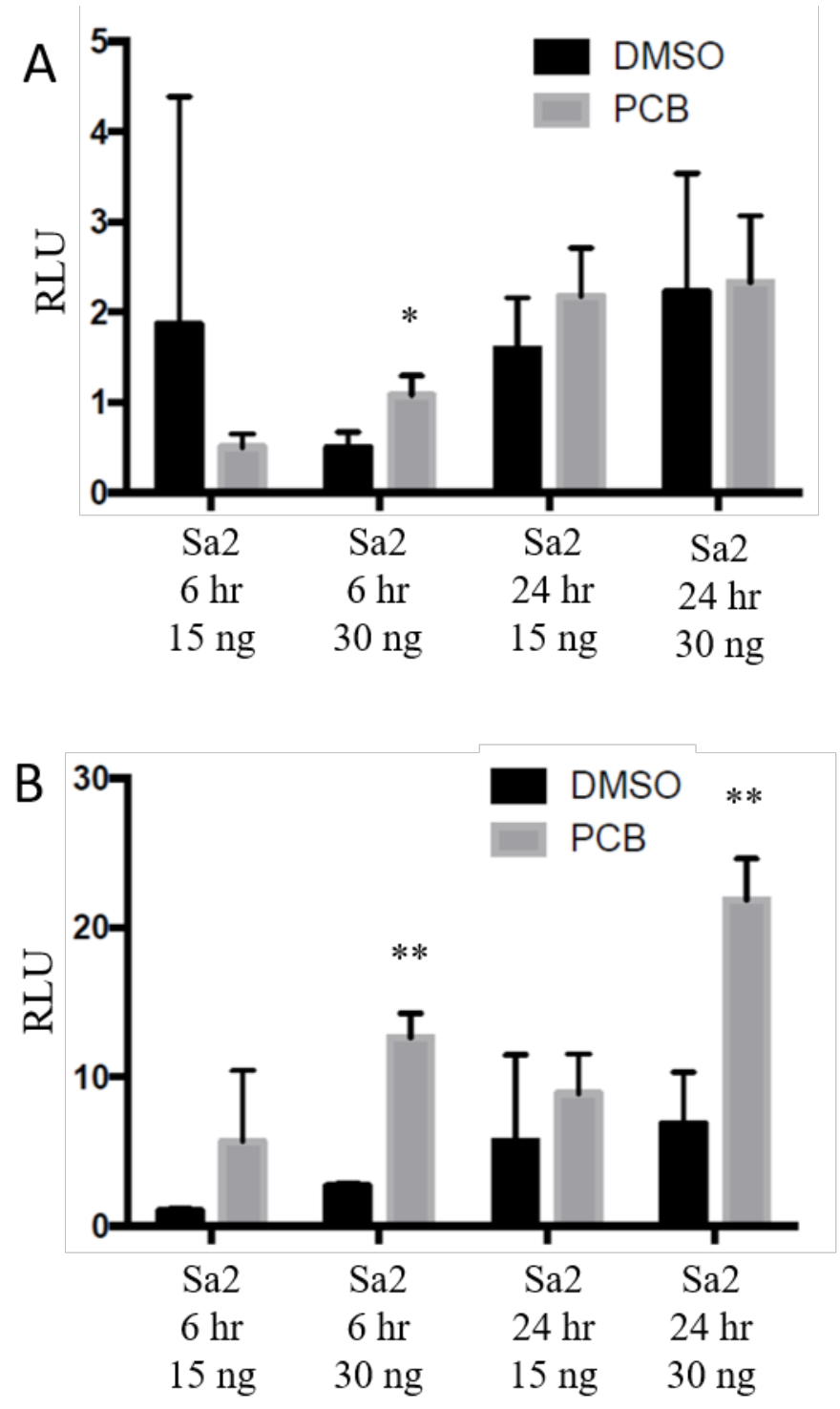

Appendix 9: Luciferase assays 3(A) and 4(B), optimization of SaAHR2 transfection amount (15 ng vs. $30 \mathrm{ng}$ ) and dosing timepoint ( $6 \mathrm{hr}$ vs. $24 \mathrm{hr}$ post transfection). This experiment did not include FhARNT2 cotransfection. Bars denote mean value of triplicate wells, error bars denote 1 standard deviation. PCB 126 final concentration of $100 \mathrm{nM}$. Asterisks denote values significantly different from DMSO only control, Student's $t$ test (* $=\mathrm{P}<0.02, * *=\mathrm{P}<0.005)$. 